\title{
EFFECTS OF FAMILIARITY ON BOLDNESS IN FEMALE EASTERN MOSQUITOFISH (GAMBUSIA HOLBROOKI)
}

\author{
by \\ Pierre-Luc Brackenridge
}

\author{
A thesis submitted to \\ The Faculty of Graduate and Postdoctoral Affairs \\ in partial fulfillment of the requirements for the degree of
}

\author{
Master of Science \\ in \\ Biology \\ Department of Biology \\ Carleton University \\ Ottawa, Ontario, Canada
}

4 January, 2011

(C) Pierre-Luc Brackenridge 
Library and Archives

Canada

Published Heritage

Branch

395 Wellington Street

Ottawa ON K1A 0N4

Canada
Bibliothèque et

Archives Canada

Direction du

Patrimoine de l'édition

395 , rue Wellington

Ottawa ON K1A ON4

Canada
Your file Votre référence

ISBN: 978-0-494-81690-5

Our file Notre référence

ISBN: 978-0-494-81690-5
NOTICE:

The author has granted a nonexclusive license allowing Library and Archives Canada to reproduce, publish, archive, preserve, conserve, communicate to the public by telecommunication or on the Internet, loan, distribute and sell theses worldwide, for commercial or noncommercial purposes, in microform, paper, electronic and/or any other formats.

The author retains copyright ownership and moral rights in this thesis. Neither the thesis nor substantial extracts from it may be printed or otherwise reproduced without the author's permission.
AVIS:

L'auteur a accordé une licence non exclusive permettant à la Bibliothèque et Archives Canada de reproduire, publier, archiver, sauvegarder, conserver, transmettre au public par télécommunication ou par l'Internet, prêter, distribuer et vendre des thèses partout dans le monde, à des fins commerciales ou autres, sur support microforme, papier, électronique et/ou autres formats.

L'auteur conserve la propriété du droit d'auteur et des droits moraux qui protège cette thèse. $\mathrm{Ni}$ la thèse ni des extraits substantiels de celle-ci ne doivent être imprimés ou autrement reproduits sans son autorisation.
In compliance with the Canadian Privacy Act some supporting forms may have been removed from this thesis.

While these forms may be included in the document page count, their removal does not represent any loss of content from the thesis.
Conformément à la loi canadienne sur la protection de la vie privée, quelques formulaires secondaires ont été enlevés de cette thèse.

Bien que ces formulaires aient inclus dans la pagination, il n'y aura aucun contenu manquant. 


\section{Abstract}

The preference to associate with familiar conspecifics and the potential effects of the presence of familiar individuals on the boldness (i.e. tendency to take risks under predation threat) of female Eastern mosquitofish (Gambusia holbrooki) were examined in this thesis. A dichotomous choice experiment was used to test for a focal fish's preference to associate with either a stimulus shoal of familiar individuals or a shoal of unfamiliar individuals. The effects of familiarity on boldness were assessed by recording separately risk-taking behaviour of focal fish in the presence of a realistic bass model predator and its latency to return to feed following a simulated heron attack. Female mosquitofish did not significantly prefer to associate with familiar conspecifics, and they were not significantly bolder in the presence of familiar conspecifics as opposed to unfamiliar conspecifics. However, there was a significant correlation between the above two boldness measures, as well as a significant interaction between an individual's boldness in inspecting a bass model and the familiarity of nearby conspecifics on the latency to return to feed following an avian attack. The results suggest that the preference for familiar individuals may not be selected for in the study population owing to large shoal sizes in the wild, and that the composition of a nearby conspecific shoal may influence an individual's boldness. 


\section{Acknowledgements}

First, I would like to thank my supervisor Dr. Jean-Guy Godin for the opportunity he has provided me and for his invaluable guidance throughout this project. I would also like to thank my committee members, Dr. Steve Cooke and Dr. Tom Sherratt, for their insight and advice which greatly improved my thesis.

Recognition and appreciation is extended to all of the lab members in the Godin lab (Stacey Lee-Jenkins, Alex Wilson, Sarah Jeswiet, Adam Densmore, Patrick Barks, Heather Auld and Rebecca Warmington) who have become great friends along the way.

Last but not least, thank you to my family and friends (Darwin's Bulldogs, Strikers) for all of your support throughout the years. 


\section{Table of Contents}

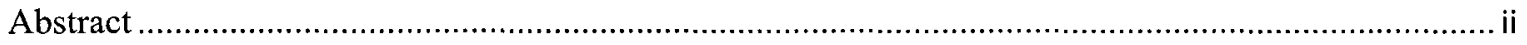

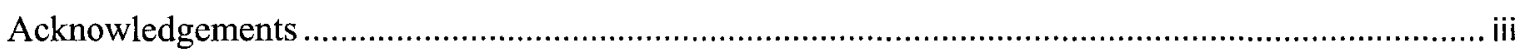

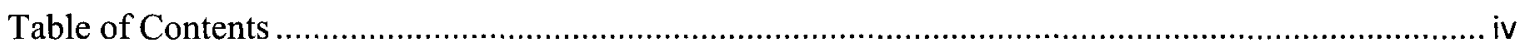

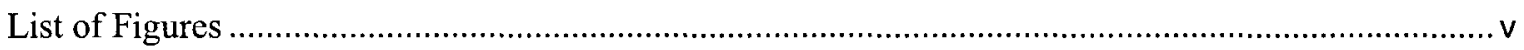

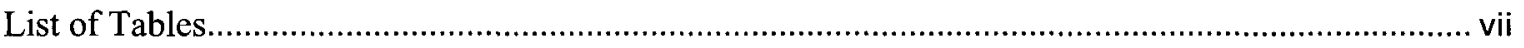

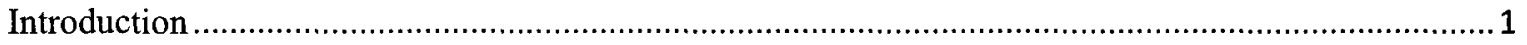

Group living, familiarity and personality: an overview ........................................................ 1

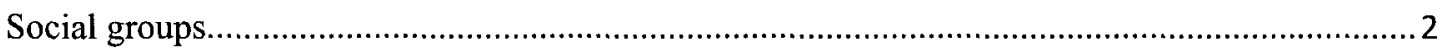

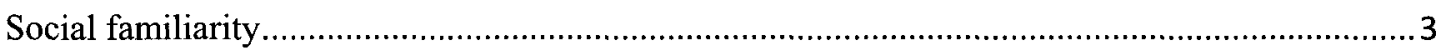

Development of social familiarity and recognition of familiar individuals .................................. 4

Factors affecting preference for familiar individuals ........................................................... 5

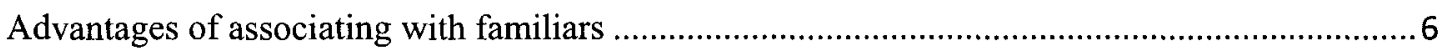

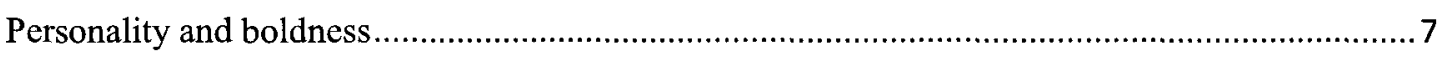

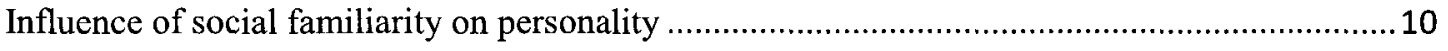

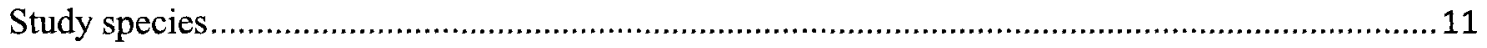

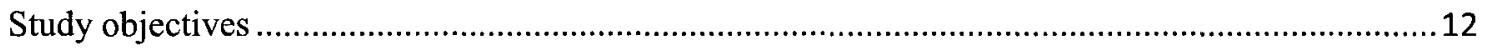

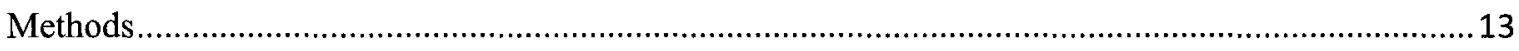

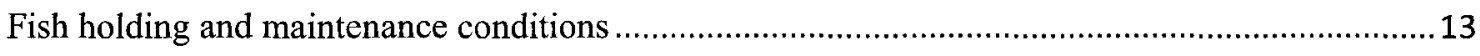

Experiment 1: Testing for a familiarity preference …….......................................................... 14

Experiment 2: Testing for an effect of familiarity on boldness ...................................................18

Part A: Boldness assessment - predator inspection behaviour ................................................ 18

Part B: Effects of familiarity - latency to feed following a predator attack ..............................20

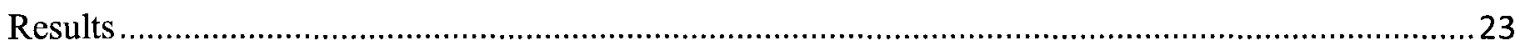

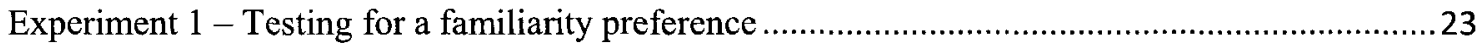

Experiment 2 - Testing for an effect of familiarity on boldness.................................................25

Part A: Boldness assessment - predator inspection behaviour................................................ 25

Part B: Effects of familiarity - latency to feed following a predator attack ..............................31

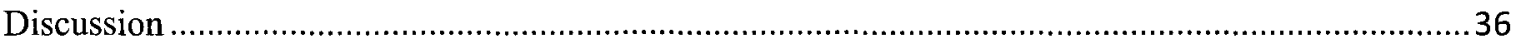

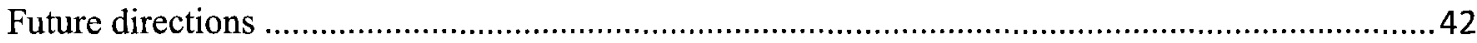

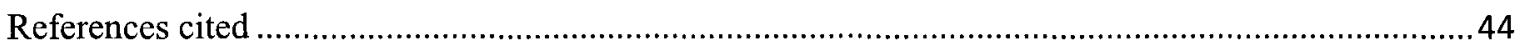




\section{List of Figures}

Figure 1. Top-view schematic of the experimental aquarium for the dichotomous choice experiment (Experiment 1). The dotted lines delineate the $10-\mathrm{cm}$ wide preference zones, and the solid lines represent clear, perforated dividers constraining the two stimulus shoals. The circle denotes a clear, perforated cylinder in which the focal fish was temporarily placed at the onset of a trial.

Figure 2. Top-view schematic of the experimental aquarium for quantifying predator inspection behaviour (Experiment 2, Part A). The dotted line represents a removable opaque partition, and the circle denotes a clear, perforated cylinder left empty in Experiment 2, Part A. Inset picture of the bass model used in the experiment is shown.

Figure 3. Top-view schematic of the experimental apparatus for Experiment 2, Part B on the latency to return to feed following a simulated avian attack. The dotted line represents an opaque, removable partition, the small grey circle represents the food cup and the white rectangle represents the heron model. The left circle delineates a clear, perforated cylinder in which the stimulus shoal was placed. Inset pictures of the heron model and the food cup are shown above.

Figure 4. Observed shoal sampling frequency $(A, C)$ and the proportion of time spent near familiars $(B, D)$ for fish tested in sequential order (first or second) in the $\mathrm{F} 1$ population (A, B) and wild population (C, D). Box plots represent the $25^{\text {th }}, 50^{\text {th }}$ and $75^{\text {th }}$ percentiles, with the whiskers showing the minimum and maximum values which are not outliers.

Figure 5. Mean (+SD) proportion of time focal fish spent associating with familiars when compared to that expected by chance (stippled, horizontal line, $\mathrm{p}=0.50$ ) for two Eastern mosquitofish populations (F1 and Wild). Pvalues shown were obtained using the t-test. $\mathrm{N}=$ sample size.

Figure 6. Relationship among three predator inspection variables and their respective correlation coefficients and p-values. 
Figure 7. Frequency distribution of the composite boldness scores (shybold axis) for wild-caught mosquitofish when faced with a simulated fish predation threat.

Figure 8. Frequency distribution of the latency to return to feed (in seconds) following an avian attack (A) and the $\log _{10}$ transformed distribution (B), which was similar to a normal distribution.

Figure 9. Relationship between the focal fish's initial composite boldness score and the focal fish's latency to return to feed following a simulated avian attack in the presence of a stimulus shoal of either familiar or unfamiliar conspecifics. The lines shown were obtained from a linear regression analysis. The familiar stimulus shoal subgroup had an $\mathrm{R}^{2}$ value of 0.71 , while the unfamiliar stimulus shoal group had an $R^{2}$ value of 0.20 .

Figure 10. Composite boldness score (PC1) when inspecting a bass model for focal fish tested either with a familiar or an unfamiliar stimulus shoal. 


\section{List of Tables}

Table 1. Mean proportions of time spent associating with familiars and Pvalues for the two mosquitofish populations (F1 and Wild). The t-test statistics shown are comparing the observed proportion of time that focal fish spent associating with familiars in each trial when compared to that expected by chance (i.e. 0.50 )

Table 2. Percent of total variation in boldness behaviour explained by the three original predator inspection variables and their loadings on the composite boldness score (PC1).

Table 3. Parameters and significance for the variables included in the ANCOVA model using type III sums of squares. The overall model had an $R^{2}$ value of 0.569 .

Table 4. Parameters and significance for the variables included in the ANCOVA model using type I sums of squares. The overall model had an $\mathrm{R}^{2}$ value of 0.569 


\section{Introduction}

This thesis examines the potential effect of social familiarity with conspecifics on risk-taking behaviour (i.e. boldness) in female Eastern mosquitofish (Gambusia holbrooki). By assessing any preference for familiar conspecifics and the effects of associating with familiar individuals over unfamiliar individuals on risk-taking behaviour, I will address the question: are individuals bolder when they are near familiar conspecifics than otherwise. The thesis consists of the following sections: an overview of the literature on familiarity and boldness, description of the model study species and the study's objectives; a description of my experimental methodology; the results of the experiments; and a discussion of these results.

\section{Group living, familiarity and personality: an overview}

In this section, I will first review the relevant literature on social living and association preferences in fishes, followed by the role that social familiarity has on shoaling decisions. Then, I summarize sequentially existing knowledge on the development of familiarity in individual fish, the recognition of familiar individuals, the factors which may influence the preference for familiar individuals and the advantages of associating with familiars. Individual personality and boldness are defined and described in fishes, followed by an overview of studies examining the effects of familiarity on various aspects of personality. 


\section{Social groups}

Group living is a common phenomenon in the animal kingdom (Krause and Ruxton, 2002). In fishes, groups are commonly defined as shoals or schools. A shoal is an aggregation of fishes, together for social reasons (with no implications on structure or function of the group) (Pitcher and Parrish, 1993). In comparison, fish schools are synchronized and polarized swimming groups (Pitcher and Parrish, 1993). Shoals are typically non-random associations of individuals, which are assorted by species (Krause and Godin, 1994; Barber et al., 1998; Hoare et al., 2000), body size (Krause et al., 1996; Hoare et al., 2000), colour (McRobert and Bradner, 1998) and parasite load (Barber et al., 1998; Hoare et al., 2000). Fish may also associate in shoals with individuals based on their diet (Ward et al., 2004; Morrell et al., 2007), habitat cues (Ward et al., 2004; Webster et al., 2007), the competitive ability of individuals (Metcalfe and Thomson, 1995), predator experience (Alfieri and Dugatkin, 2009) and, at times, by social familiarity and kinship (Krause and Ruxton, 2002). Fish shoals are fission-fusion groups (Krause and Ruxton, 2002), as individuals constantly join and leave groups based on the costs and benefits of membership in the group. Benefits to individuals of membership in a group include reduced predation risk and increased foraging efficiency (Krause and Ruxton, 2002). However, living in groups also has some disadvantages, such as increased competition for food, an increased risk of being infected by parasites and other pathogens, and increased conspicuousness to predators (Krause and Ruxton, 2002; Botham et al., 2005). 


\section{Social familiarity}

When deciding to join a social group or not, an individual may use information on its relative familiarity with individuals in that group. Familiarity can be defined as the recognition and/or preference to associate with individuals based on previous experience of interacting with them (Magurran et al., 1994; Griffiths, 2003). A preference to associate with familiar individuals has been established in many taxa, including mammals (Porter et al., 2005), birds (Wiley et al., 1999), insects (Clark et al., 1995) and multiple species of fish (three-spined stickleback, Gasterosteus aculeatus, Barber and Ruxton, 2000; bluegill sunfish, Lepomis macrochirus, Dugatkin and Wilson, 1992; Trinidadian guppy, Poecilia reticulata, Magurran et al., 1994; banded killifish, Fundulus diaphanus, Lee-Jenkins and Godin, 2009; European minnow, Phoxinus phoxinus, Griffiths, 1997). Moreover, the blacktail shiner (Cyprinella venusta) and the Texas shiner (Notropis amabilis) both exhibited a preference and stronger shoaling tendencies towards familiar conspecifics (Farmer et al., 2004). Preference for familiar individuals may even outweigh the preference for larger groups, as shown in the Trinidadian guppy which prefer familiar shoals nearly half the size of unfamiliar shoals (Barber and Wright, 2001). The preference for familiars can even be extended to heterospecifics, that is, individuals of a different species (Ward et al., 2003). These preferences have been demonstrated mainly in laboratory experiments using dichotomous choice experiments, as controlled laboratory conditions may exaggerate the effects of familiarity due to the lack of mixing between shoals for extended periods of time. Few studies have found support for a preference for familiars in free-ranging fish in the wild (Hay and McKinnell, 2002; Ward 
et al., 2002), as there is very little evidence of shoal fidelity in the wild (Helfman, 1984; Hoare et al., 2000; Krause et al., 2000).

Additionally, an individual fish may or may not choose to associate with a particular shoal of conspecifics based on whether individuals in that shoal are familiar with each other. For example, individual three-spined sticklebacks preferred to associate with unfamiliar shoals consisting of individuals which were familiar with one another, as opposed to unfamiliar shoals consisting of individuals which were unfamiliar to one another (Ward and Hart, 2005).

\section{Development of social familiarity and recognition of familiar individuals}

Preference for familiar individuals in fishes develops over an extended period of time. In female guppies, preference for familiars became apparent only after 12 days of remaining in the same group (Griffiths and Magurran, 1997a; Croft et al., 2004). This preference for familiars can also persist after long periods of isolation. For example, female guppies preferred to associate with familiar conspecifics even after five weeks of isolation (Bhat and Magurran, 2006). Recognition of familiars appears to be based primarily on visual and olfactory cues. The relative importance of these types of cues in recognizing familiars is dependent on the species. In fathead minnows (Pimephales promelas) and three-spined sticklebacks, preference for familiars was significant in the presence of olfactory cues, but not visual cues only (Brown and Smith, 1994; Ward et al., 2004). In female guppies, however, individuals preferred to associate with familiar individuals even when visual cues only were presented (Magurran et al., 1994). Some fish species have also been found to be more aggressive towards unfamiliar individuals 
on the basis of visual cues only (three-spined stickleback, Waas and Colgan, 1994; cichlid, Neolamprologus pulcher, Frostman and Sherman, 2004). This leads to two contrasting views regarding the number of fish that one individual can recognize. If the recognition of familiar fish is based mostly on an olfactory cue, the number of fish that any one individual can recognize may be quite large if there is a general common odour cue for the group. However, if the recognition is based on individual characteristics, there may be a cognitive upper-limit to the number of conspecifics that one individual may recognize. The latter scenario is supported in female Trinidadian guppies where the preference for familiar individuals is inversely related to the number of individuals in the group (Griffiths and Magurran, 1997b).

\section{Factors affecting preference for familiar individuals}

Preference to associate with familiar individuals is influenced by a number of factors. First, preference for familiars has been shown to decrease with increasing group size in the guppy (Griffiths and Magurran, 1997b). Preference may also vary based on the sex of the individuals interacting socially. In the guppy, females tend to prefer to associate with familiar individuals, but males do not show any preference (Griffiths and Magurran, 1998). Second, preference for familiars may vary based on the nutritional state of the choosing individual, as hungry individuals shoal less and spend more time alone than in shoals compared to more satiated individuals (Barber et al., 1995; Hensor et al., 2003; Krause et al., 1999). Similarly, satiated sticklebacks preferred to associate with familiars, whereas hungry individuals showed no such preferences (Frommen et al., 2007). Therefore, hungry fish may be more concerned with the risk of competition associated with group living, than the increased risk of competition from foraging for 
food alone or in an unfamiliar group (Hensor et al., 2003). Lastly, social rank may also affect preference for familiars. In angelfish (Pterophyllum scalare), subordinate fish preferred familiar subordinate fish and unfamiliar dominant fish, whereas dominant fish did not prefer either familiar or unfamiliar fish (subordinate or dominant) (GómezLaplaza and Fuente, 2007).

\section{Advantages of associating with familiars}

In addition to the fitness-related advantages of living in groups, associating with familiar individuals also confers several advantages. For example, shoaling with familiars can increase the occurrence of cooperative antipredator behaviour. In fathead minnows, shoals of familiar fish were more cohesive when predator chemical cues were presented, and familiar fish conducted more predator inspections (sensu Dugatkin and Godin, 1992) and with more inspectors per inspection when presented with a predator model than unfamiliar fish (Chivers et al., 1995). Associating with familiar individuals may also lead to a reduction in aggressive and competitive encounters between members of a group. Commonly referred to as the "dear enemy phenomenon" (Jaeger, 1981), one would expect the number of aggressive encounters to decrease as the number of encounters between individuals increase when familiar individuals interact socially. This phenomenon has been described in various taxa, including frogs (Bee and Gerhardt, 2001), lizards (Qualls and Jaeger, 1991; Fox and Baird, 1992) and birds (Godard and Wiley, 1995). The reduction of aggressive and competitive behaviours can then lead to increased sharing of food (Utne-Palm, 2000), lower mortality rates (Seppä et al., 2001), faster foraging (Höjesjö, 1998, Griffiths et al., 2004) and higher growth rates (Seppä et al., 2001). Another benefit may be increased social learning in the presence of familiars. 
In the Trinidadian guppy, a test fish was more likely to complete a maze to reach a food source faster in the presence of familiar conspecifics than with unfamiliar conspecifics (Swaney et al., 2001). Similarly, individual three-spined sticklebacks were faster and more effective at locating prey items when foraging with familiar than unfamiliar conspecifics (Ward et al., 2005). Recognizing and shoaling with familiar individuals is more likely to be beneficial in social species, such as the guppy and three-spined stickleback, than in territorial species, such as the pumpkinseed sunfish (Lepomis gibbosus) and rockbass (Ambloplites rupestris) (Ward and Hart, 2003).

Additionally, recognition of familiar from unfamiliar individuals may be important in mate choice. For example, male guppies in a confined pool directed more courtship towards novel, unfamiliar females, whereas males from open rivers had no preference towards either familiar or unfamiliar females (Kelley et al., 1999). Such differential behaviour based on familiarity may lead to increased gene flow within fish populations that may be spatially confined for extended periods in the wild, such as in the dry season (Kelley et al., 1999).

\section{Personality and boldness}

Within social groups, individuals commonly vary in their willingness to take risks (i.e. they vary along a bold-shy continuum; Wilson et al., 1994; Sih et al., 2004). Personality (or temperament) can be defined as individual differences in behaviour which are consistent across situations and/or time (Réale et al., 2007). In this context, being consistent does not necessarily mean that the trait does not change, but rather that relative differences in behaviour between individuals remain largely the same. Animal 
personality can be placed into five major categories: shyness-boldness, explorationavoidance, activity, aggressiveness and sociability (Réale et al., 2007).

Boldness is commonly defined as the willingness to take risks in non novel situations, such as prey approaching predators (Dugatkin and Godin, 1992; Réale et al., 2007). It is also referred to as investigative behaviour, predator inspection behaviour, predator harassment or mobbing, depending on the outcome of the inspection (Dugatkin and Godin, 1992). Boldness has been linked to several life-history traits such as dispersal (Fraser et al., 2001), growth rate (Ward et al., 2004) and reproductive fitness (Godin and Dugatkin, 1996; Both et al., 2005; Wilson et al., 2010). Boldness is heritable and is dependent on life experiences, such as exposure to predation risk (Brown et al., 2007).

Predator inspection behaviour is typically characterized by the prey animal (the inspector) visually fixating the predator whilst slowly moving towards it in a series of alternating moves and pauses (Dugatkin and Godin, 1992; Pitcher, 1992). Benefits of approaching a predator include acquiring information about the nature of the threat (such as whether the predator is satiated or dangerous) and possibly deterring a predatory attack by harassing the predator or removing the element of a surprise attack (Dugatkin and Godin, 1992; Godin and Davis, 1995). However, costs of approaching a predator include increased risk of mortality (Milinski et al., 1997), lost opportunities (less time foraging) (Dugatkin and Godin, 1992), and the possibility of being exploited by conspecifics while inspecting a predator (Magurran and Nowak, 1991; Wilson et al., 2010). Prey will commonly avoid the riskier, most dangerous part of the predator's body (such as its head) during predator inspection to minimize the risk of mortality, a phenomenon termed “attack cone avoidance" (Dugatkin and Godin, 1992; Pitcher, 1992). Prey will also vary 
their antipredator behaviour and inspections based on the predator species that they are exposed to (Botham et al., 2006). Although prey may detect the nearby presence of a predator using chemical cues, they may modify their antipredator behaviour based on the perceived threat of a predator using visual cues (Chivers et al., 2001). Learned recognition of predators by predator-naive individuals using a combination of visual and chemical cues can be acquired in as little as two days (Chivers and Smith, 1994).

Predator inspections are most commonly carried out alone or in pairs (Dugatkin and Godin, 1992; Pitcher, 1992). Predator inspection behaviour can be affected by the perceived threat (Murphy and Pitcher, 1997). For example, more inspections and larger groups of inspectors may occur shortly following an attack (Murphy and Pitcher, 1997). According to the growth-mortality trade-off hypothesis (Stamps, 2007), bolder individuals should be more likely to take risks when foraging under higher predation risk (which should lead to higher growth rates), but in doing so they will incur a greater risk of mortality to predation. For example, bolder pumpkinseed sunfish (Lepomis gibbosus) forage more often and in riskier situations than shy pumpkinseed sunfish, which could lead to higher growth rates (Wilson et al., 1994). Similarly, bolder killifish (Rivulus hartii) have higher growth rates compared to shy killifish and disperse further in fragmented, high-hazard environments (Fraser et al., 2001). Faster growing, bolder rainbow trout (Oncorhynchus mykiss) were harvested in an experimental gillnet fishery at a significantly higher rate than the slower growing, shy individuals (Biro and Post, 2008). It has been further hypothesized that consistent individual differences in boldness might be related to consistent differences in life history traits, such as growth rate and fecundity (Ward et al., 2004; Biro and Stamps, 2008). Therefore, individuals with a faster growth 
rate might be bolder because they must forage more often to grow fast, thereby exposing themselves to predators (Ward et al., 2004; Biro and Stamps, 2008). In rainbow trout, experimentally increasing growth hormone concentrations in individuals led to higher levels of hunger and bolder behaviour (Jönsson et al., 1996). Similarly, hungry fish are more likely to initiate predator inspections and are thus considered bolder in inspecting a potential predator (Godin and Crossman, 1994).

Personality can also influence the spatial organization of fish within a shoal. Peripheral positions within a shoal tend to be more susceptible to predator attacks, although they are more advantageous for foraging (Krause and Ruxton, 2002). Although bolder individuals exhibit lower shoaling tendencies, bolder three-spined sticklebacks and golden shiners both tended to occupy riskier positions near the front of a shoal as members of a group (Ward et al., 2004; Leblond and Reebs, 2007). Additionally, bold fish are generally less sociable, shoal less strongly and are more active, whether they are alone or in group, than shy (Pike et al., 2008).

\section{Influence of social familiarity on personality}

Little is known about the potential effects of associating with familiar group mates on individual personality. Most studies on fishes to date have focused on the effects of familiarity on aggression and the "dear enemy" phenomenon (e.g. Leiser and Itzkowitz, 1999; Frostman and Sherman, 2004). Utne-Palm and Hart (2000) noticed decreased aggression in groups of familiar three-spined stickleback. This decreased aggression led to an increased sharing of prey items among fish pairs, which may also lead to higher growth rates, better body condition and increased individual survival 
within the group (Seppä et al., 2001). Few studies have examined the effects of social familiarity on exploration or boldness. In one such study, Trinidadian guppies emerged sooner from a refuge when in the presence of familiars than unfamiliars (Bhat and Magurran, 2006). In another study, groups of familiar minnows exhibited more inspections and more individuals were recruited to inspect a model predator (indices of increased boldness) in the presence of familiar conspecifics than unfamiliar ones (Chivers et al., 1995). Therefore, there is a need for more studies on whether familiarity with nearby conspecifics modifies a focal individual's boldness.

\section{Study species}

Using the Eastern mosquitofish (Gambusia holbrooki) as a model system, I investigated experimentally whether individuals prefer to socially associate with familiar conspecifics and whether such associations based on familiarity affect individual boldness. Female Eastern mosquitofish are livebearing, active shoalers that commonly occur in very large shoals in nature (Pyke, 2005). Along with the Western mosquitofish (Gambusia affinis), they are abundantly found on all continents except for Antarctica (Pyke, 2005). Female Eastern mosquitofish can produce multiple broods per season and their clutches vary between 5 and 100 young (Pyke, 2005). In the wild, Eastern mosquitofish feed on a wide variety of foods, including insects, crustaceans, molluscs, smaller fish and algae (Pyke, 2005). Although the Eastern mosquitofish is an active shoaling species, individuals can be aggressive towards conspecifics and often establish dominance hierarchies within groups (Pyke, 2005). Their mating system is promiscuous and coercive. There is little evidence of courtship displays, and mating consists mostly of aggressive gonopodial thrusts by the male (Pyke, 2005). Mosquitofish exhibit 
considerable variation in individual boldness and dispersal tendency (Cote et al., 2010; Wilson et al., 2010), and their ability to disperse may explain their broad geographical distribution (Rehage et al., 2004; Pyke, 2005).

Eastern mosquitofish are similar in many ways to the Trinidadian guppy. Both are poeciliids (Family Poeciliidae), livebearers and active shoalers. Although preference for familiars has yet to be established in the Eastern mosquitofish, this species could provide a very useful model for studying group association behaviour and boldness owing to its widespread geographical distribution and abundance in nature (Pyke, 2005).

\section{Study objectives}

The primary objective of my study was to ascertain whether individual female Eastern mosquitofish are bolder in the presence of familiar conspecifics compared with unfamiliar coonspecifics. First, I tested whether individual fish could behaviourally distinguish between familiar and unfamiliar conspecifics in a dichotomous choice experiment. Then, a composite boldness score for each focal fish was obtained by quantifying an individual's predator inspection behaviour towards a predator bass model when alone. Finally, the latency of focal fish to return to a food patch following a simulated avian attack, in the presence of a constrained shoal of familiar or unfamiliar conspecifics, was used to test for any effect of familiarity on an individual's boldness. I predicted that female mosquitofish would exhibit a significant preference for familiar fish, given that the mosquitofish is an active shoaling species. If mosquitofish do prefer to associate with familiars, then I predict that they would be bolder in the presence of familiars. Alternatively, if mosquitofish do not prefer to associate with familiar 
individuals, then I predict that the boldness of focal fish would not be influenced by the presence of either familiar or unfamiliar conspecifics nearby. Unlike Chivers et al. (1995), I investigated variation in the boldness of individual fish rather than group-level variation in boldness/antipredator response.

\section{Methods}

\section{Fish holding and maintenance conditions}

Wild Eastern mosquitofish were collected from the Tampa Bay Canal in Florida and obtained through a commercial fish supplier (Aqua Tropicale) in Montréal in February, 2009. Males and females were initially kept together in a large $295 \mathrm{~L}$ aquarium (123 cm x $46 \mathrm{~cm}$ x $52 \mathrm{~cm}$ ). In early December 2009, adult female mosquitofish were divided into six groups, ranging from six to ten individuals each, and transferred in separate $60 \mathrm{~L}$ aquaria $(62 \mathrm{~cm} \times 31 \mathrm{~cm} \times 33 \mathrm{~cm})$ each containing a single male. The fish were maintained in these aquaria for approximately eight weeks to develop familiarity among each other within each group. Gravid females were isolated in smaller $20 \mathrm{~L}$ aquaria $(41 \mathrm{~cm} \times 21 \mathrm{~cm} \times 25 \mathrm{~cm})$ and five broods were produced (F1 generation). The $\mathrm{F} 1$ broods were kept in separate $20 \mathrm{~L}$ aquaria, except for one large brood which was split into two aquaria. All holding aquaria were visually and chemically isolated from one another and each aquarium contained a gravel substratum, a heater, a corner filter and an aquarium plant. The aquaria were filled with aged and aerated tap water maintained at 25-27 ${ }^{\circ} \mathrm{C}$ and illuminated with fluorescent lights on a 13L: 11D illumination cycle. During Experiment 1, the fish were fed ad libitum once daily with frozen bloodworms, frozen brine shrimp or flake food (Tetramin tropical flakes). During Experiment 2, the 
fish were conditioned daily to feed on frozen bloodworms presented in a floating food cup in their home holding aquarium. During both experiments, fish were fed at the end of the day (approximately 16:00 hrs) to ensure that they were equally motivated to feed during Experiment 2. Each of the F1 groups were separately considered kin and familiar with each other, whereas individuals within each wild-caught groups were considered familiar with one another. Although it was not possible to exclude the possibility that the latter fish were kin, the probability of this being the case is quite small due to the large number of individuals initially collected haphazardly by seine in the field. Only mature females were used as focal fish.

\section{Experiment 1: Testing for a familiarity preference}

A standard dichotomous choice protocol (e.g. Lee-Jenkins and Godin, 2009) was used to ascertain whether female mosquitofish preferred associating with a stimulus shoal of familiar conspecifics or a shoal of unfamiliar conspecifics. The test aquarium ( $75 \mathrm{~L} ; 76$ $\mathrm{cm} \times 31.5 \mathrm{~cm} \times 32 \mathrm{~cm}, \mathrm{LxWxH}$ ) was externally covered with tan paper on all four sides to minimize external disturbances, and the bottom of the aquarium was covered with a fine, light coloured gravel. The aquarium (Figure 1) was divided into three compartments by two clear, perforated plastic dividers that allowed visual and chemical cues to be transmitted between the stimulus shoals and focal fish. The two dividers were positioned $10 \mathrm{~cm}$ from either end of the aquarium. Lines were drawn on both sides of the aquarium and a $20-\mathrm{cm}$ long, narrow blue piece of plastic was positioned in the gravel $10 \mathrm{~cm}$ from each divider, thereby delineating a $10-\mathrm{cm}$ wide "shoal preference zone" adjacent to each end compartment. The width of the preference zones corresponds to about three fish body lengths, which falls within the inter-individual distances observed in wild fish shoals 


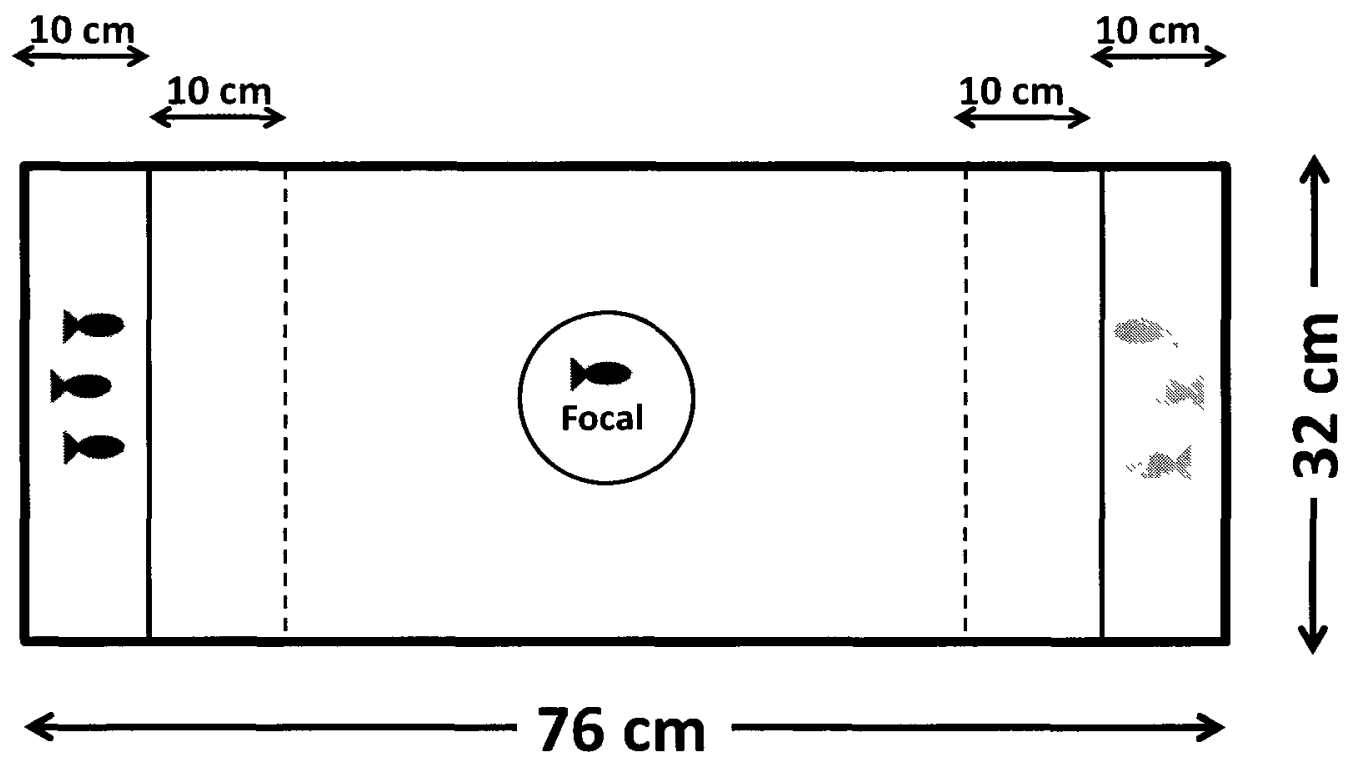

Figure 1. Top-view schematic of the experimental aquarium for the dichotomous choice experiment (Experiment 1). The dotted lines delineate the $10-\mathrm{cm}$ wide preference zones, and the solid lines represent clear, perforated dividers constraining the two stimulus shoals. The circle denotes a clear, perforated cylinder in which the focal fish was temporarily placed at the onset of a trial. 
(Pitcher and Parrish, 1993). An aquarium heater and an airstone maintained water temperature close to that of the stock tanks and the water aerated, respectively. The heater and airstone were removed prior to the introduction of fish to the experimental aquarium.

A stimulus shoal consisting of three familiar individuals was introduced into one end compartment of the aquarium and another stimulus shoal consisting of three unfamiliar individuals was introduced into the opposite end compartment. Group choice and aquarium side allocation were selected using a random number generator (www.random.org). Individuals in each paired stimulus shoals were similar in body length, with an average standard length of $2.45 \mathrm{~cm}$ and $2.30 \mathrm{~cm}$ for the left and right stimulus shoals, respectively, for the $\mathrm{F} 1 \mathrm{fish}(\mathrm{t}=1.751, \mathrm{df}=9, \mathrm{P}=0.114)$, and $3.31 \mathrm{~cm}$ and $3.30 \mathrm{~cm}$ for the left and right stimulus shoals, respectively, for the wild fish $(\mathrm{t}=$ $0.186, \mathrm{~d} f=11, \mathrm{P}=0.856$ ). Once the stimulus shoals were introduced into their end compartments, a single focal fish from the same stock tank as the familiar stimulus shoal was placed in a clear, perforated plastic cylinder $(10-\mathrm{cm}$ diameter $)$ in the centre of the aquarium. The fish was allowed $10 \mathrm{~min}$ to acclimatize and view the paired stimulus shoals before being released remotely from behind a dark, plastic screen. The trial commenced once the focal fish resumed swimming after being released. The behaviour of the focal fish was videorecorded with a Sony Handycam (HDR-HC7) camera placed overhead for a 15 -min trial. The total time that the focal fish spent in each preference zone, and facing the stimulus shoal, was recorded from the video tapes. Once the trial was completed, the standard length of the focal fish was measured, following which it was returned into a separate compartment in its original home stock tank. Another focal fish was then selected from the same group as the previously unfamiliar shoal and placed 
into the clear, plastic cylinder for another trial (with the same stimulus shoals). Once this second trial was completed, the standard length for both focal and stimulus fish were measured, and all fish were returned to their respective stock tanks in a separate compartment. Individual focal fish were used only once. However, because of the limited number of fish available, previously tested fish (focal fish and stimulus shoals) were used more than once as a stimulus shoal. The same pair of stimulus shoals was used only twice on the same day (with any reciprocal pair of focal fish). A total of 20 and 24 focal fish were tested from the F1 and Wild lab populations, respectively. Two focal fish from each population did not sample both stimulus shoals, and were excluded from subsequent analyses (final sample sizes: $\mathrm{F} 1 \mathrm{~N}=18$, Wild $\mathrm{N}=22$ ).

From the videotapes, time spent by a focal fish within each preference zone was quantified using JWatcher (Blumstein and Daniel, 2007). The proportion of time spent with familiars excluded time spent in the neutral zone and thus consisted of the proportion of the time spent associating with familiars divided by the time spent shoaling with both stimulus shoals. The mean proportion of time spent near familiars was then compared using a t-test to the proportion expected by chance $(p=0.50)$ if there was no preference for familiars. All proportions were arcsin transformed to normalize the distributions. 


\section{Experiment 2: Testing for an effect of familiarity on boldness}

\section{Part A: Boldness assessment - predator inspection behaviour}

Because of the small number of fish and broods available, large differences in sizes among broods and the potential confounding of familiarity and kinship in the labborn (F1) fish, only the wild fish was used for Part 2 of the experiment.

The boldness level of individual fish (in the absence of any conspecifics) was assessed prior to investigating the potential effect of the familiarity of "shoal" mates on their boldness. The initial boldness measure of focal fish was based on their "inspecting" a fish predator model (e.g. Godin and Crossman, 1994). The experimental aquarium (75 L; $76 \mathrm{~cm} \times 31.5 \mathrm{~cm} \times 32 \mathrm{~cm}$ ) was covered on all four sides by tan paper to minimize external disturbances, contained a gravel substrate and was illuminated overhead. A clear, perforated plastic cylinder $(10 \mathrm{~cm}$ diameter) was placed $5 \mathrm{~cm}$ from one end of the aquarium and a removable opaque partition was positioned $20 \mathrm{~cm}$ from the same end of the aquarium to create a starting compartment for the focal fish (Figure 2). A heater and an airstone maintained water temperature close to that in the stock tanks and the water aerated, respectively. They were removed from the test aquarium prior to the trial starting. The focal fish was introduced into this compartment of the aquarium. Once the focal fish resumed normal activity, the partition was raised remotely and the fish allowed to swim freely within the test aquarium for $15 \mathrm{~min}$. Following this acclimatization period, the fish was gently guided back towards the start compartment and the opaque partition was replaced. A realistic 3-D model of a largemouth bass (Micropterus salmoides) was then placed at the other end of the aquarium and broadside to the compartment at the 

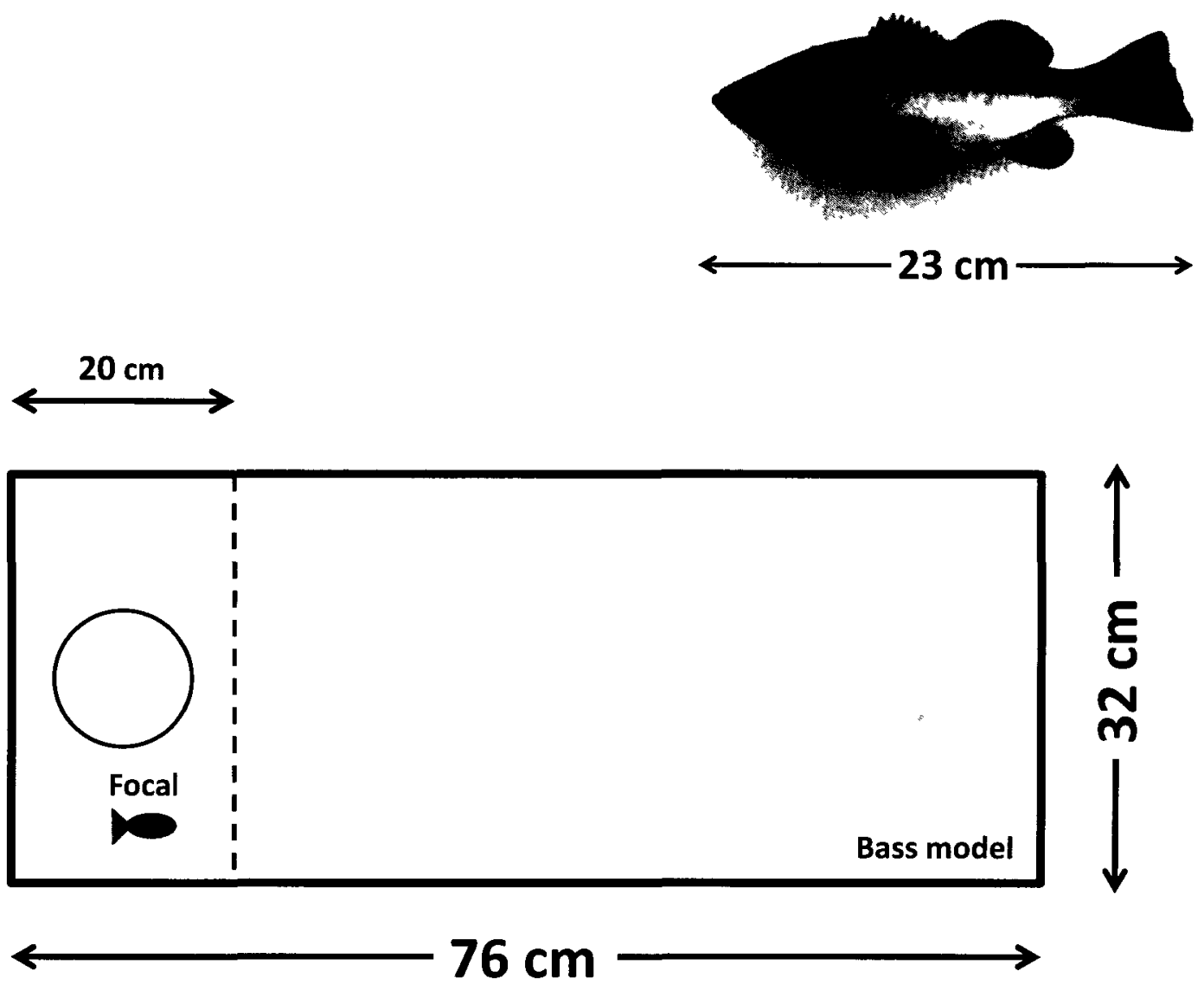

Figure 2. Top-view schematic of the experimental aquarium for quantifying predator inspection behaviour (Experiment 2, Part A). The dotted line represents a removable opaque partition, and the circle denotes a clear, perforated cylinder left empty in Experiment 2, Part A. Inset picture of the bass model used in the experiment is shown. 
opposite end of the aquarium (Figure 2). The model was suspended in mid-water column with monofilament lines attached to a small piece of clear Plexiglas overhead. After an additional $5 \mathrm{~min}$ had elapsed, the opaque partition was again raised remotely, and the fish was allowed to swim freely and approach the bass model. A 5-min trial began once the fish resumed activity. Trials were recorded with a Sony Handycam (HDR-HC7) video camera placed overhead. Once the trial was completed, the focal fish was once again gently guided back to the start position, the opaque partition was replaced to constrain the fish within the start zone, and the bass model was then removed from the aquarium in preparation for Part B of the experiment.

The number of approaches towards the predator model by the focal fish, the total time spent in approaches, and the average minimum (closest) distance to the model were measured using JWatcher (Blumstein and Daniel, 2007) and ImageJ (Ferreira and Rasband, 2010). These predator inspection variables were intercorrelated (refer to Figure 6). Consequently, they were collapsed into a single composite boldness score for each fish using the Principal Components Analysis (PCA).

\section{Part B: Effects of familiarity - latency to feed following a predator attack}

The boldness of focal fish was assessed by quantifying the latency of the focal fish to return to feed from a floating food cup following a simulated avian attack on the fish whilst in the presence of a shoal comprising of either familiar or unfamiliar conspecifics (Jönsson et al., 1996; Bell, 2005; Réale et al., 2007). A realistic wooden model of the head-neck region of the great-blue heron (Figure 3) was attached to a metal 

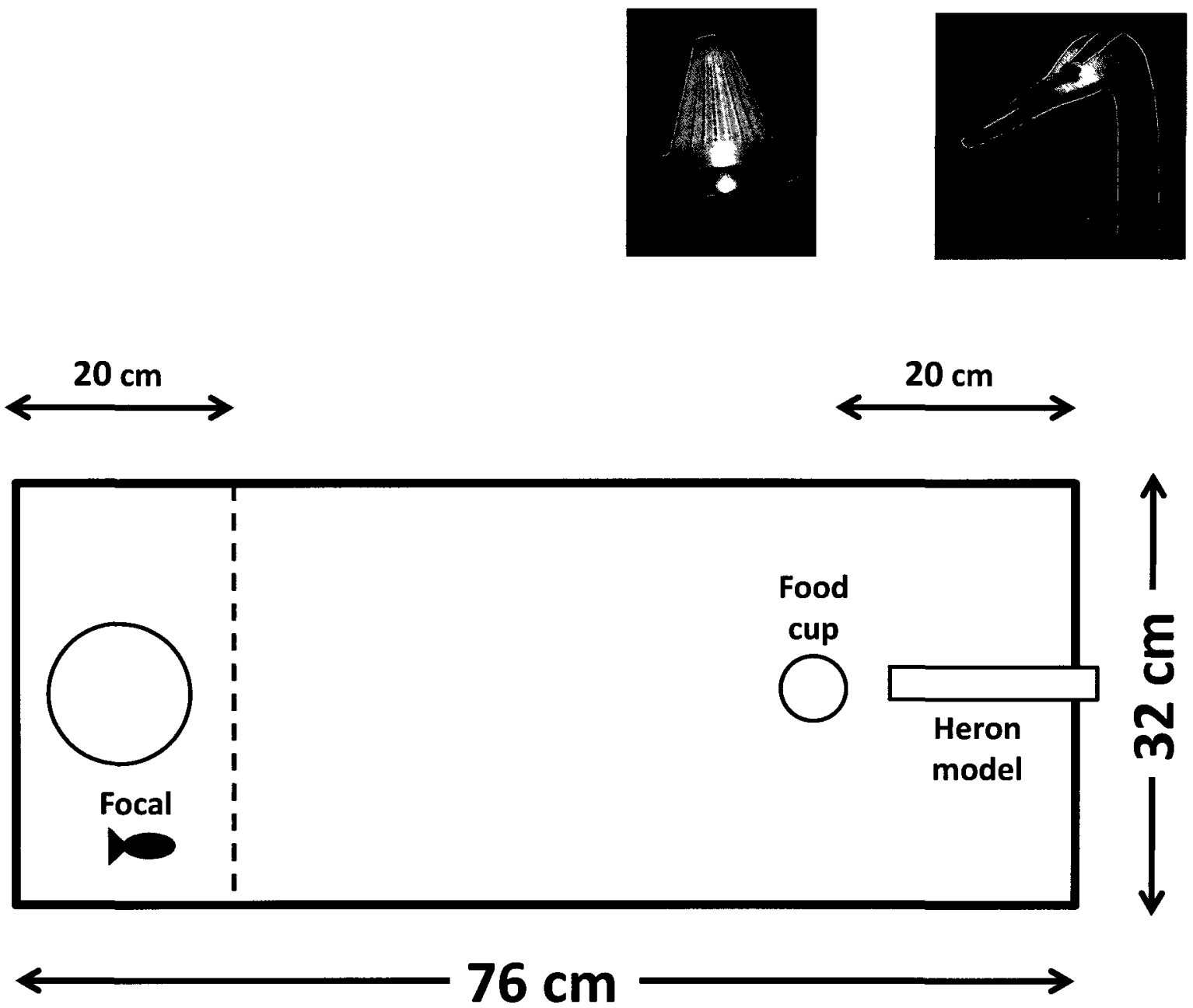

Figure 3. Top-view schematic of the experimental apparatus for Experiment 2, Part B on the latency to return to feed following a simulated avian attack. The dotted line represents an opaque, removable partition, the small grey circle represents the food cup and the white rectangle represents the heron model. The left circle delineates a clear, perforated cylinder in which the stimulus shoal was placed. Inset pictures of the heron model and the food cup are shown above. 
frame surrounding (but not attached to) the test aquarium. The heron model was set to simulate a single strike; it was spring loaded and it could be dropped so that its beak was submerged completely near the floating food cup, without touching the edges of the aquarium, and retrieved remotely from behind the plastic screen. The duration of a simulated attack was about 1 sec. After the focal fish was constrained by an opaque partition in the start zone at the end of Part A of the experiment, a floating food cup was placed $20 \mathrm{~cm}$ from the opposite end of the aquarium, just below the overhead model heron (Figure 3). A stimulus shoal of two fish, comprised of either familiar or unfamiliar individuals to the focal fish, was then introduced into a clear, perforated plastic cylinder located in the start zone (Figure 3). The focal fish and stimulus fish were left undisturbed for $10 \mathrm{~min}$ to associate with each other. Following this period, frozen bloodworms were placed into the food cup using a long pipette from behind the screen, so as to not disturb the fish. The opaque partition was then lifted to allow the focal fish to feed at the food cup. Once the focal fish had bitten the food cup 2-3 times, the heron model was dropped to simulate an attack. Typically, the attack frightened the focal fish such that it ceased foraging and either froze on the substrate near the food cup or fled towards the stimulus shoal at the opposite end of the test tank; these responses are typical anti-predator behaviours in fishes (Godin, 1997). The trial ended once the fish returned to feed at the food cup. Trials were recorded using a Sony Handycam (HDR-HC7) video camera placed overhead. For each of the focal fish, latency to return to feed (time elapsed from the instant of predator model "attack" to fish returning to feed at the food cup) was recorded from the video tapes. A total of 27 focal fish were tested. However, two focal fish did not feed initially and two other fish were excluded from the data set because their 
latencies to return to the feeding cup (808 and 249 seconds, respectively) were statistical outliers. Therefore, a total of 23 fish were included in the analysis.

The data on latency to return to feed after a simulated avian attack were not normally distributed and were therefore $\log _{10}$ transformed. Distributions were tested for normality using the Kolmogorov-Smirnov test. The t-test was used to compare the mean transformed latency to return to feed between focal fish with a familiar or unfamiliar stimulus shoal. Also, an analysis of covariance (ANCOVA) was conducted on the data with the following components: the $\log _{10}$ transformed latency to return to feed as the dependent variable, the familiarity of the stimulus shoal as the fixed factor, the composite predator inspection boldness score (PC1) as the covariate, and the interaction between familiarity and the composite boldness score. All statistical analyses were carried out using SPSS v17.0.

\section{Results}

\section{Experiment 1 - Testing for a familiarity preference}

The order in which the trials were run had no effect on the focal fish's shoal sampling frequency $(\mathrm{F} 1: \mathrm{df}=7, \mathrm{t}=0.460, \mathrm{P}=0.660$, Figure $4 \mathrm{a}$; Wild: $\mathrm{df}=9, \mathrm{t}=0.693, \mathrm{P}$ $=0.506$, Figure $4 \mathrm{c})$ nor on the preference for familiars $(\mathrm{F} 1: \mathrm{df}=7, \mathrm{t}=-0.946, \mathrm{P}=0.376$, Figure 4b; Wild: $\mathrm{df}=9, \mathrm{t}=-0.441, \mathrm{P}=0.670$, Figure $4 \mathrm{~d}$ ). The $\mathrm{F} 1$ fish shoaled $71.7 \pm$ $12.4 \%$ of the time (mean $\pm \mathrm{SD}$ ), compared to $48.8 \pm 15.1 \%$ for the wild fish. The F1 fish shoaled $53 \%$ of the time with familiar individuals, whereas the wild fish spent $47 \%$ of the 

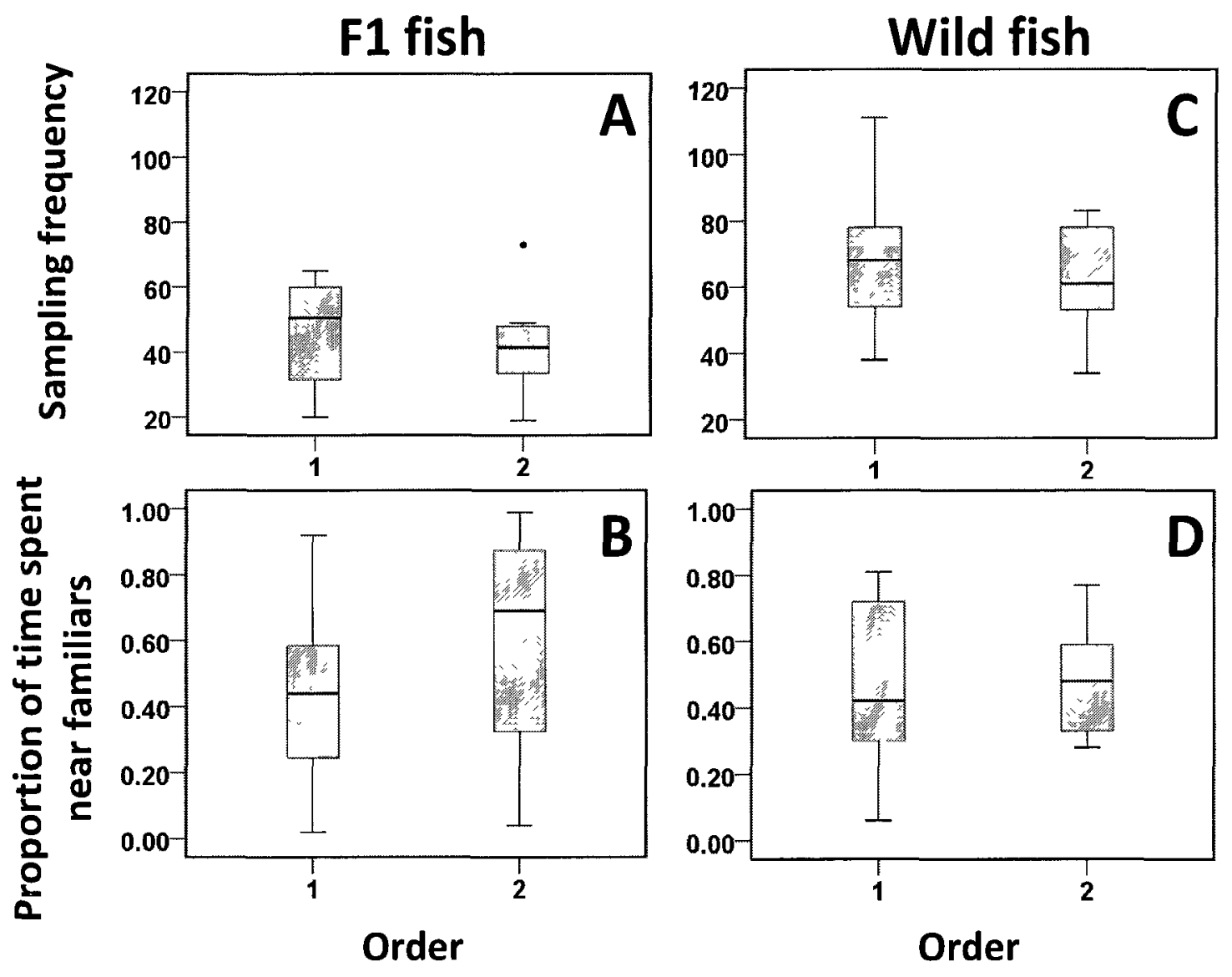

Figure 4. Observed shoal sampling frequency $(\mathrm{A}, \mathrm{C})$ and the proportion of time spent near familiars (B, D) for fish tested in sequential order (first or second) in the $F 1$ population $(A, B)$ and wild population $(C, D)$. Box plots represent the $25^{\text {th }}, 50^{\text {th }}$ and $75^{\text {th }}$ percentiles, with the whiskers showing the minimum and maximum values which are not outliers. 
time associating with familiars. Neither population significantly preferred to shoal with familiar conspecifics over unfamiliar ones (Table 1; Figure 5). Time spent shoaling with familiars was not significantly different between the $\mathrm{F} 1$ and Wild fish $(\mathrm{df}=38, \mathrm{t}=-0.756$, $\mathrm{P}=0.454 ;$ Figure 5).

\section{Experiment 2 - Testing for an effect of familiarity on boldness}

\section{Part A: Boldness assessment - predator inspection behaviour}

The three measured variables of predator inspection behaviour (number of approaches, total time spent approaching the predator, and average minimum distance of approaches to the predator) were significantly intercorrelated, and the relationship between most variables appeared linear (Figure 6). This result justified the use of a Principal Components Analysis (PCA) to reduce the number of variables into one composite boldness score. A PCA on the three variables generated one principal component $(\mathrm{PC} 1)$ with an eigenvalue exceeding 1 (eigenvalue $=1.92) . \mathrm{PC} 1$ explained $63.9 \%$ of the overall variance in boldness behaviour and it extracted $63.4 \%$ of the number of approaches, $86.5 \%$ of the total time of approaches and $41.6 \%$ of the average minimum distance (Table 2). PC1 loaded positively on number of approaches $(0.796)$ and total time of approaches $(0.930)$ and negatively on average minimum distance $(-0.645)$ (Table 2). The resulting frequency distribution of boldness scores was not significantly different from a normal distribution (Kolmogorov-Smirnov test, $\mathrm{Z}=0.815, \mathrm{~N}=23, \mathrm{P}=0.520$; Figure 7). The observed distribution of individual boldness scores (Figure 7) represents the shybold axis for the test fish, with the majority of the fish being intermediate in their shybold behaviour and with only a few fish being extremely bold or extremely shy. 
Table 1. Mean proportions of time spent associating with familiars and P-values for the two mosquitofish populations (F1 and Wild). The t-test statistics shown are comparing the observed proportion of time that focal fish spent associating with familiars in each trial when compared to that expected by chance (i.e. 0.50 )

\begin{tabular}{lcccc}
\hline Population & $\begin{array}{c}\text { Mean proportion of time } \\
\text { spent with familiars }\end{array}$ & $\mathrm{t}$ & $\mathrm{df}$ & $\mathrm{P}$ \\
\hline F1 & 0.53 & 0.449 & 17 & 0.66 \\
Wild & 0.47 & -0.668 & 21 & 0.51 \\
\hline
\end{tabular}




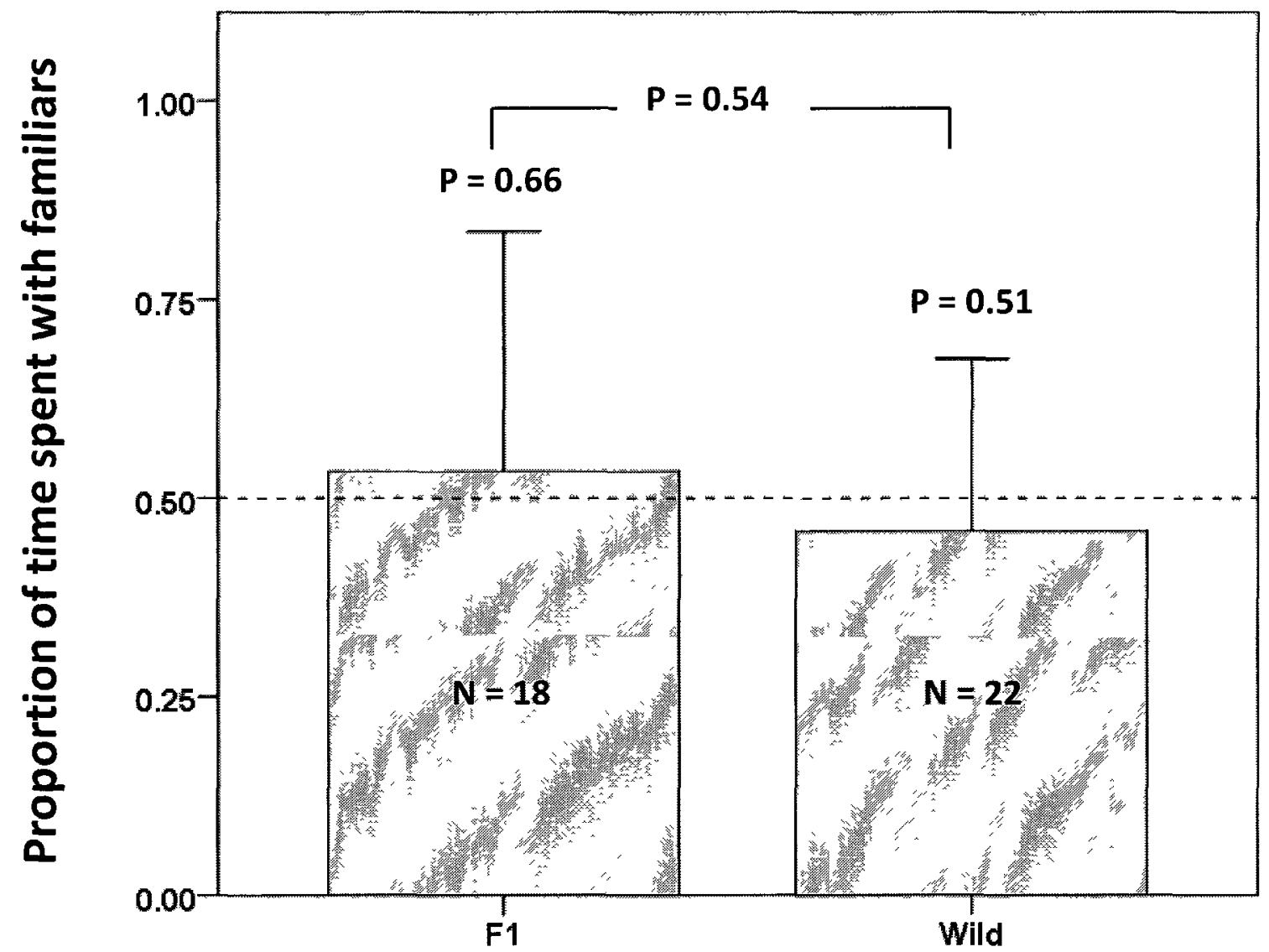

Figure 5. Mean (+ SD) proportion of time focal fish spent associating with familiars when compared to that expected by chance (stippled, horizontal line, $p=0.50$ ) for two Eastern mosquitofish populations (F1 and Wild). P-values shown were obtained using the t-test. $\mathrm{N}=$ sample size. 


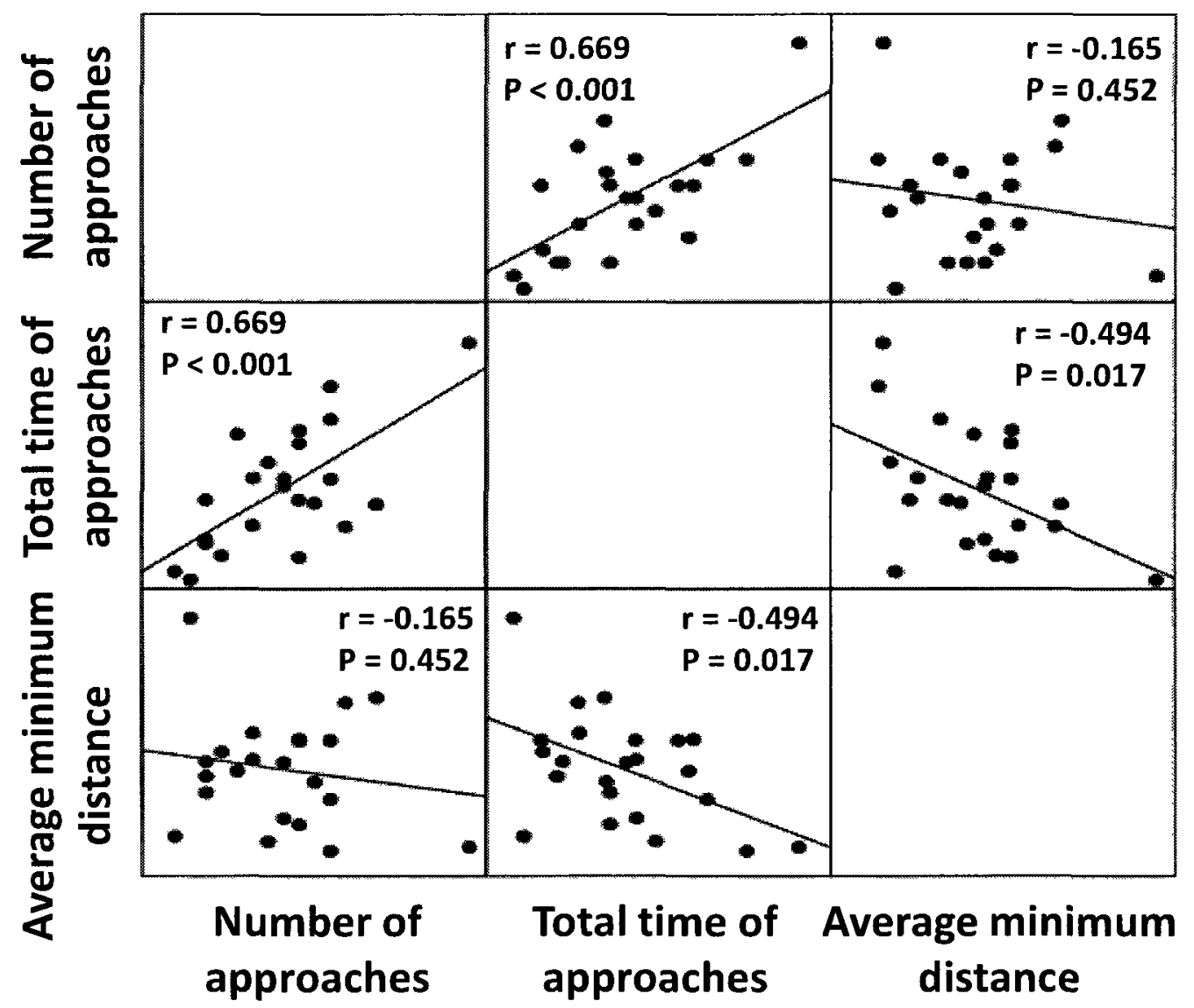

Figure 6. Relationship among three predator inspection variables and their respective correlation coefficients and $p$-values. 
Table 2. Percent of total variation in boldness behaviour explained by the three original predator inspection variables and their loadings on the composite boldness score (PC1).

\begin{tabular}{lcc}
\hline & \% variance explained & Loadings on PC1 \\
\hline Total time of approaches & 0.865 & 0.930 \\
Number of approaches & 0.634 & 0.796 \\
Average minimum distance & 0.416 & -0.645 \\
\hline
\end{tabular}




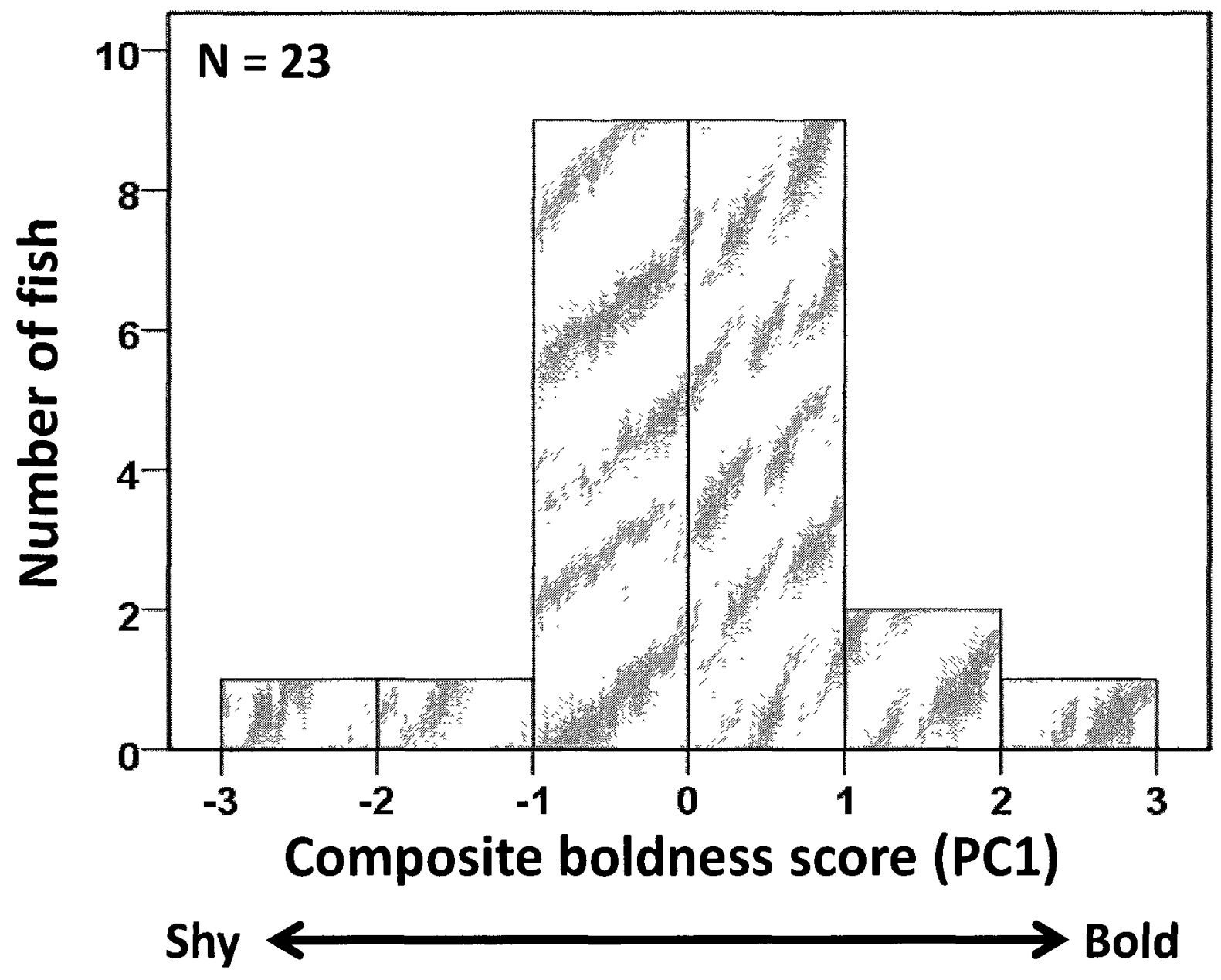

Figure 7. Frequency distribution of the composite boldness scores (shy-bold axis) for wild-caught mosquitofish when faced with a simulated fish predation threat. 


\section{Part B: Effects of familiarity - latency to feed following a predator attack}

Focal fish (boldness score $=-0.17 \pm 0.87$ ) tested with a familiar stimulus shoal were not significantly different $(\mathrm{t}=0.786, \mathrm{df}=21, \mathrm{P}=0.44)$ in their composite boldness score from focal fish $(0.16 \pm 1.12)$ tested with an unfamiliar stimulus shoal. The latency to return to feed following a simulated avian attack was on average $( \pm \mathrm{SD}) 25.5 \pm 37.8 \mathrm{~s}$ (range $=3-182 \mathrm{~s}$ ). Because the data on latency to return to feed after an attack were not normally distributed $(\mathrm{Z}=1.474, \mathrm{~N}=23, \mathrm{P}=0.026$, Figure $8 \mathrm{a})$, they were $\log _{10}$ transformed to yield a normal distribution ( $\mathrm{Z}=0.674, \mathrm{~N}=23, \mathrm{P}=0.755$; Figure $8 \mathrm{~b}$ ) before analysis.

Overall, the composite boldness score (PC1) of individual fish, as measured from predator inspection behaviour, was significantly positively correlated with their latency to return to feed after the heron attack $(\mathrm{r}=0.626, \mathrm{~N}=23, \mathrm{P}=0.001$, Figure 9). That is, fish that were bold in the face of an apparent fish predator threat also took more risk to feed (i.e. were bolder) following a simulated avian attack, and vice versa. Also, the composite boldness score appeared to be evenly distributed among focal fish tested with familiar or unfamiliar conspecifics, although the fish with the highest boldness score was tested with an unfamiliar shoal while the fish with the lowest boldness score was tested with a familiar stimulus shoal (Figure 10). Therefore, the composite boldness score and the familiarity of the stimulus shoal are only weakly associated. Using an ANCOVA model, I tested for potential effects of the composite boldness score (in the presence of the bass model) and the stimulus shoal's familiarity on the latency to return to feed after an avian attack. This analysis revealed a significant effect of the fish's composite boldness score $(\mathrm{df}=1,19, \mathrm{~F}=18.78, \mathrm{P}<0.001$; Table 3$)$, no effect of familiarity $(\mathrm{df}=$ 

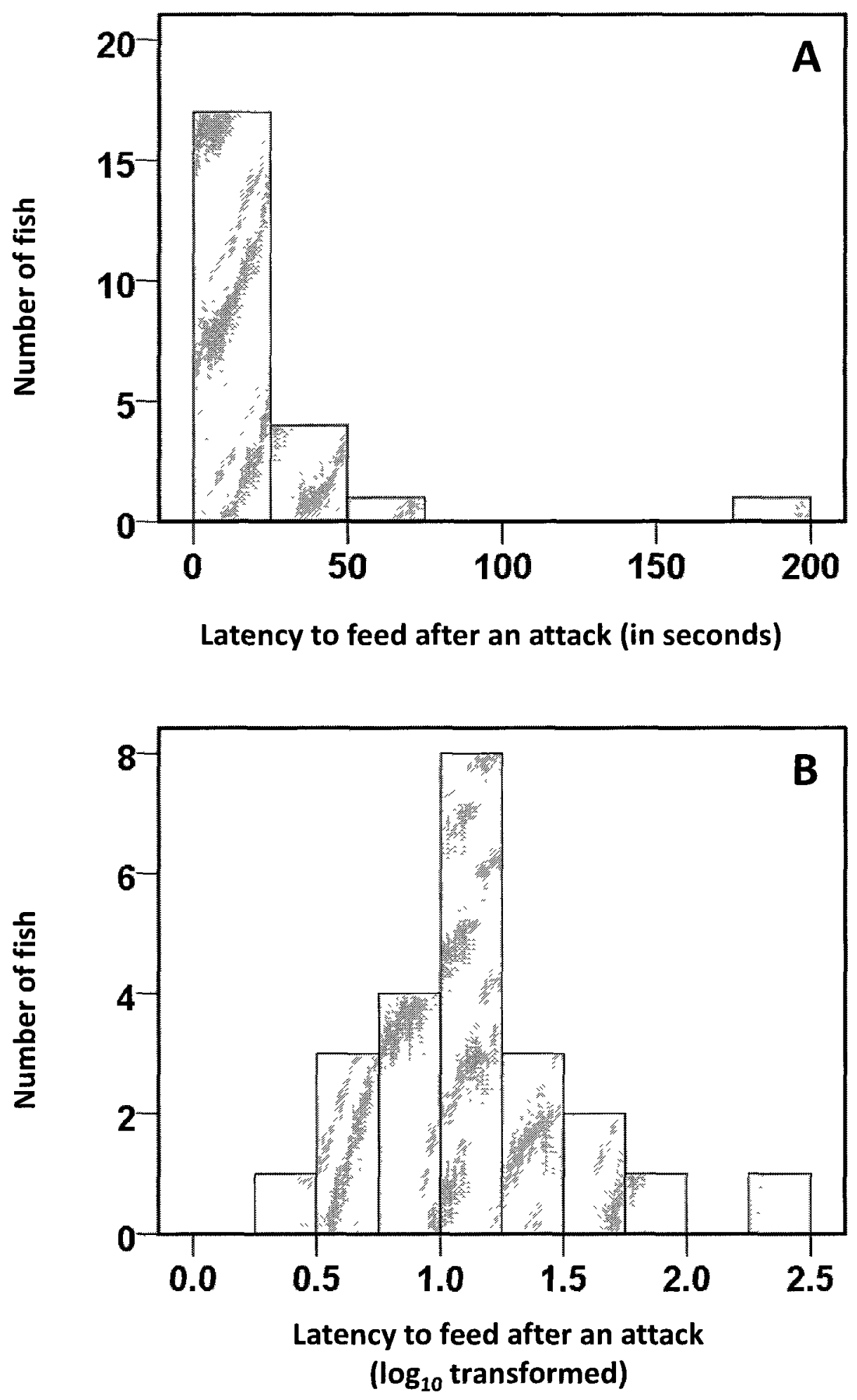

Figure 8. Frequency distribution of the latency to return to feed (in seconds) following an avian attack (A) and the $\log _{10}$ transformed distribution (B), which was similar to a normal distribution. 

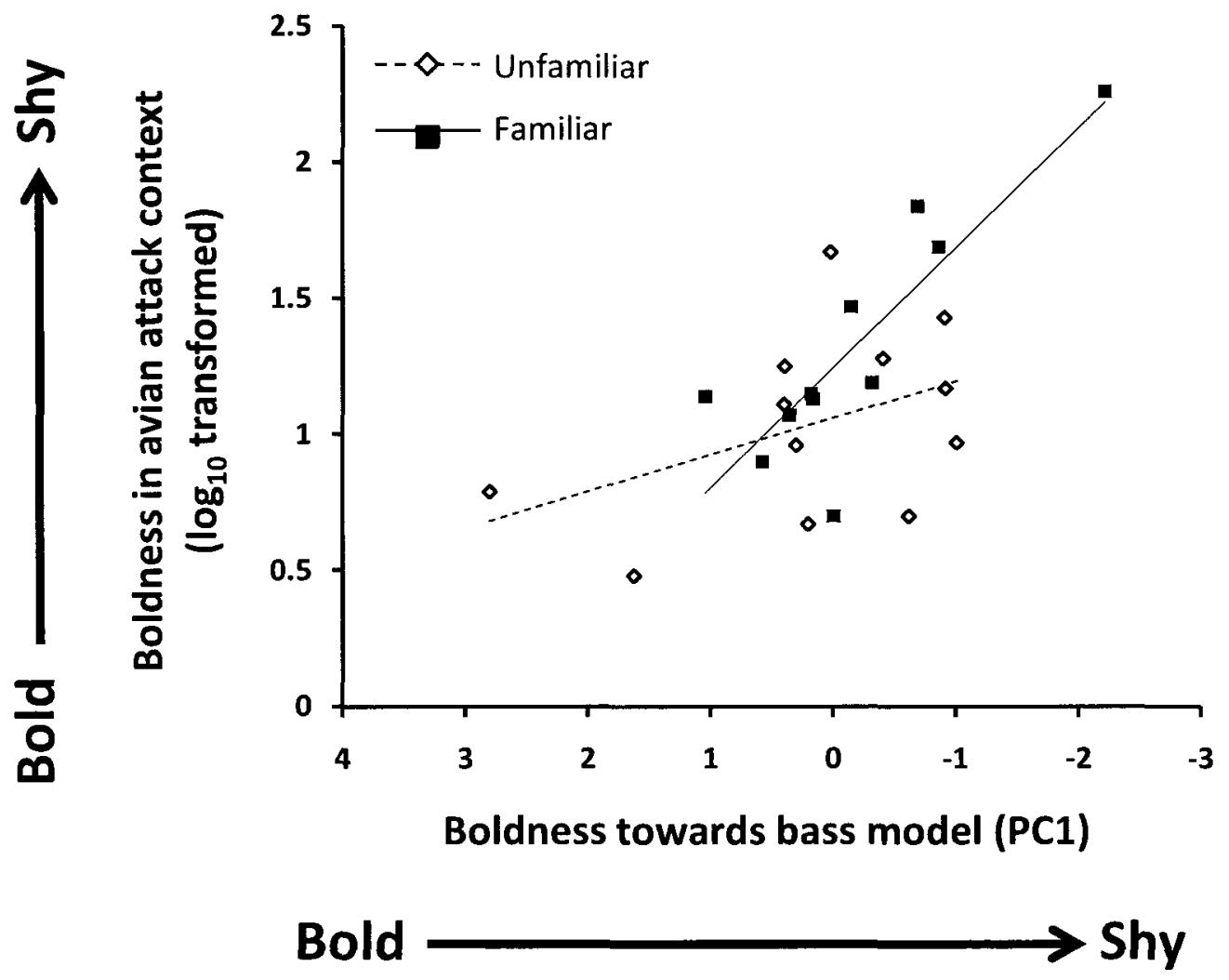

Figure 9. Relationship between the focal fish's initial composite boldness score and the focal fish's latency to return to feed following a simulated avian attack in the presence of a stimulus shoal of either familiar or unfamiliar conspecifics. The lines shown were obtained from a linear regression analysis. The familiar stimulus shoal subgroup had an $R^{2}$ value of 0.71 , while the unfamiliar stimulus shoal group had an $R^{2}$ value of 0.20 . 


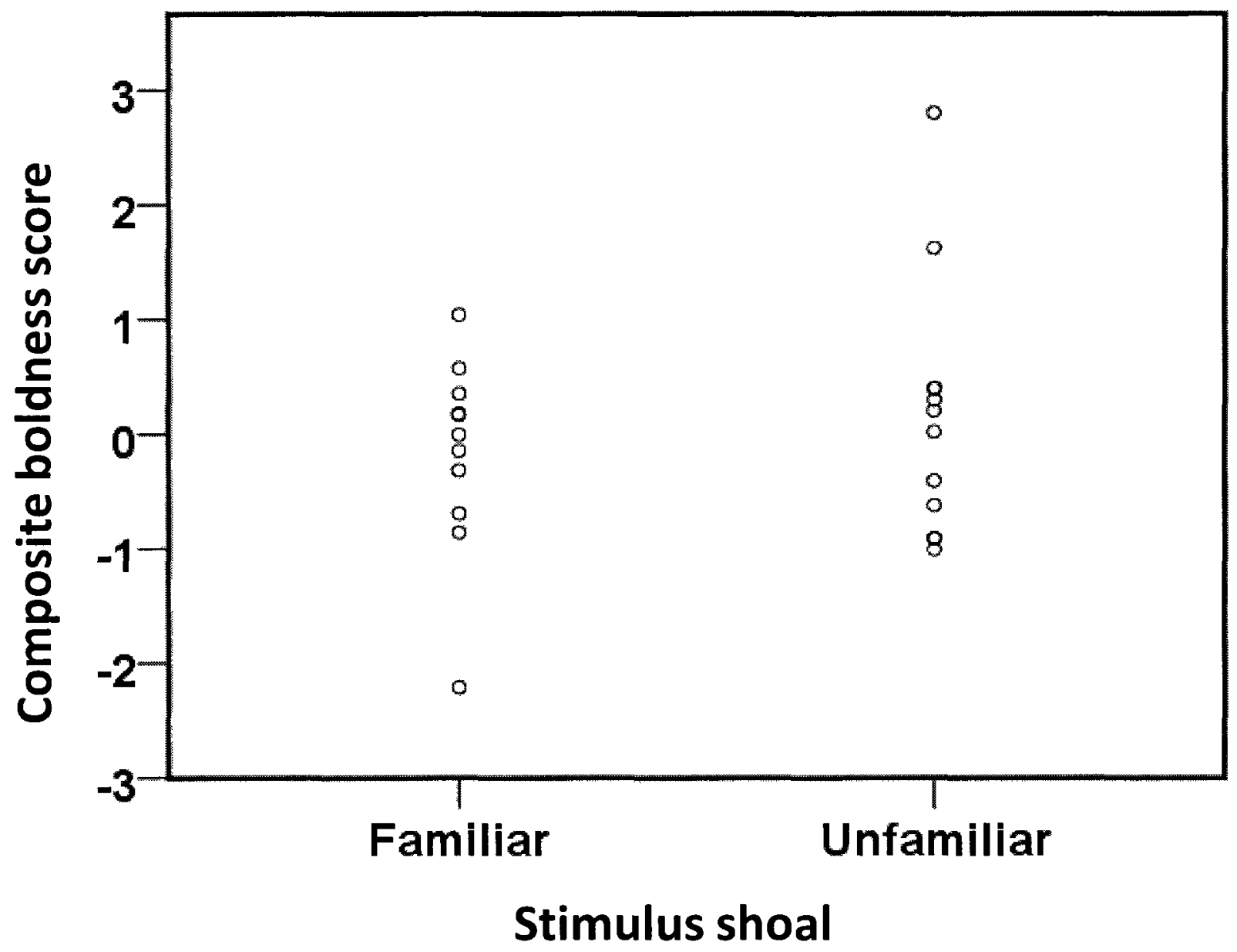

Figure 10. Composite boldness score (PC1) when inspecting a bass model for focal fish tested either with a familiar or an unfamiliar stimulus shoal. 
Table 3. Parameters and significance for the variables included in the ANCOVA model using type III sums of squares. The overall model had an $\mathrm{R}^{2}$ value of 0.569 .

\begin{tabular}{lcccc}
\hline Source & df & Mean squares & F & P \\
\hline Corrected Model & 3 & 0.725 & 8.35 & 0.001 \\
Intercept & 1 & 29.556 & 340.54 & $<0.001$ \\
Familiarity & 1 & 0.185 & 2.13 & 0.161 \\
Composite boldness score & 1 & 1.630 & 18.78 & $<0.001$ \\
Interaction & 1 & 0.453 & 5.22 & 0.034 \\
(Familiarity x boldness score) & & & & \\
Error & 19 & 0.087 & & \\
Total & 23 & & & \\
\hline
\end{tabular}


$1,19, \mathrm{~F}=2.13, \mathrm{P}=0.161$ ), and a significant interaction between the composite boldness score and familiarity $(\mathrm{df}=1,19, \mathrm{~F}=5.22, \mathrm{P}=0.034)$ when all of the variables are controlled for using Type III sum-of-squares in the ANCOVA model (Figure 9; Table 3). When the composite boldness score is not controlled for (using type I sum-of-squares in the ANCOVA model), familiarity had a significant effect on the latency to return to feed $(d f=1,19, F=5.196, P=0.034$, Table 4).

The aforementioned significant statistical interaction is reflected in a difference in the gradient relating the two boldness measures, that is, the relationship between the two boldness measures is much steeper when the focal fish are in the presence of familiar conspecifics (slope $=0.44$, Figure 9) than in the presence of unfamiliar conspecifics (slope $=0.14$, Figure 9). The power of this model to detect a significant effect of the familiarity of the stimulus shoal on the focal fish's latency to return to feed after a simulated avian attack was low (effect size $=0.101$, power $=0.283)$.

\section{Discussion}

The current study examined (i) the shoaling preference of adult female mosquitofish for socially familiar conspecifics over unfamiliar ones and (ii) the effects of the familiarity of nearby conspecifics on the risk-taking behaviour of focal individuals. My results show that females did not prefer to associate with either familiar or unfamiliar conspecifics when given a choice, and females were not, on average, bolder in the presence of familiar conspecifics compared with unfamiliar ones. However, the relationship between the boldness of focal fish when faced with a simulated fish predator 
Table 4. Parameters and significance for the variables included in the ANCOVA model using type I sums of squares. The overall model had an $R^{2}$ value of 0.569 .

\begin{tabular}{lcccc}
\hline Source & $\mathrm{df}$ & Mean square & $\mathrm{F}$ & $\mathrm{P}$ \\
\hline Corrected Model & 3 & 0.725 & 8.35 & 0.001 \\
Intercept & 1 & 31.731 & 365.60 & 0.000 \\
Familiarity & 1 & 0.451 & 5.20 & 0.034 \\
Composite boldness score & 1 & 1.270 & 14.64 & 0.001 \\
$\begin{array}{l}\text { Interaction } \\
\text { (Familiarity x boldness score) }\end{array}$ & 1 & 0.453 & 5.22 & 0.034 \\
Error & 19 & 0.087 & & \\
Total & 23 & & & \\
\hline
\end{tabular}


threat and an avian predator threat was dependent on the familiarity status of a nearby shoal of conspecifics (i.e. was context dependent).

Neither the F1 or wild mosquitofish preferred to "shoal" with familiar conspecifics (Figure 5 and Table 1). Association preferences in the dichotomous choice experiment were defined as being within $10 \mathrm{~cm}$ of the stimulus shoal and the focal fish facing the stimulus shoal. This measure is more conservative than ones used in several previous studies, where association preference had been measured by being within $2-3$ body lengths of a stimulus shoal (e.g. Magurran et al., 1994) or being located within the same half of the tank as the stimulus shoal (e.g. Farmer et al., 2004). It is unlikely that the orientation of the focal fish (in relation to the stimulus shoal) within the preference zone had a significant impact on the result since focal fish spent little time facing away from the stimulus shoal while in the preference zone. Therefore, preference for familiars may not have been selected for in my study population of the Eastern mosquitofish due to the large membership sizes of shoals in the wild (J.-G.J. Godin, unpubl. data), and consequently is not expressed in the laboratory. Large shoals may render the recognition of familiars too difficult cognitively, and it may thus reduce the preference to associate with familiars (Griffiths and Magurran, 1997). This is reinforced by the results obtained from the F1 population, as the females were kept in kin groups. The F1 focal fish did not significantly prefer to associate with kin, familiar conspecifics over non-kin, unfamiliar conspecifics.

Other possible explanations for the lack of preference for familiar individuals include previous associations with unfamiliar individuals and the level of hunger of the focal fish. Prior to the experiments, wild Eastern mosquitofish were collectively kept in a 
single $295 \mathrm{~L}$ aquarium for approximately six months, and then separated into groups of 610 individuals for approximately two months prior to the beginning of the assessment of preference of familiarity. While it is possible that they retained some of their previous association preferences, this seems unlikely because the number of individuals in the initial group was quite large (approximately 50 females) and the F1 fish also showed no preference to associate with familiar individuals. The nutritional state of the focal fish may have also influenced any preference for familiar individuals. Focal fish were fed approximately 20 hours prior to the preference trials to standardize their nutritional state in both Experiments 1 and 2. However, it is possible that this state of hunger may have reduced their time spent shoaling and their preference to shoal with familiars in search of foraging opportunities (Barber et al., 1995; Hensor et al., 2003; Frommen et al., 2007). Further studies of preference in the Eastern mosquitofish should include satiated individuals to determine whether the hunger level of focal fish impact their preference. Finally, Eastern mosquitofish may have a context-dependent preference for familiars, such that individuals may prefer to associate with familiar individuals under predation risk. Although context-dependent preference for familiar individuals has been seldom investigated, context-dependent preference for larger groups has been reported for the Eastern mosquitofish (Agrillo et al., 2006) and the banded killifish (Hoare et al., 2004). Therefore, the inclusion of a predation threat or sexual harassment could lead to enhanced grouping behaviour, such as a preference to shoal with familiar conspecifics.

The frequency distributions of the initial composite boldness score (predator inspection behaviour; Figure 7) for individual fish and their latency to return to feed after an avian attack (Figure 8) were statistically normally distributed and characterize a shy- 
bold axis of personality within the wild population, such that most individuals exhibited an intermediate level of boldness and very few individuals were very shy or very bold (Wilson et al., 2004). These two measures of boldness were positively correlated, such that bolder predator inspectors were also bolder in returning to forage under a potentially risky situation. This correlation was predicted as they are two commonly used measures of boldness (Réale et al., 2007). However, very few studies have investigated the correlation between boldness measures obtained from the same individuals in different ecological contexts, and therefore the above correlation for the Eastern mosquitofish is novel.

As expected by the lack of preference for either familiar or unfamiliar conspecific in the dichotomous choice experiment, the presence of a familiar stimulus shoal did not significantly alter the boldness of focal fish when foraging under a simulated avian predation threat when controlling for the effect of the composite boldness score (Table 3). However, the familiarity of the stimulus shoal did have a significant effect on the focal fish's latency to return to feed when the ANCOVA model does not control for the composite boldness score (Table 4). This difference between the two ANCOVA models is most likely due to the mild association between the composite boldness score in inspecting a bass model and familiarity (Figure 10). Therefore, although the effect of familiarity was significant in one of the two models, its effect overall on the latency to return to feed following an attack appears to be rather limited. Because our sample size was small for both familiarity treatment groups and the power of the ANCOVA model (using type III sum of squares) to detect a difference was low, the observed negative results should be interpreted with caution. The constraint of a small sample size could 
have been moderated by testing the focal fish repeatedly in the presence of both familiar and unfamiliar stimulus shoals over an extended period, so as to reduce the possibility of habituation to the model predator.

Nonetheless, the ANCOVA model (Tables 3 and 4) did reveal a significant interaction between familiarity of the stimulus shoal and the focal fish's composite boldness score. The relationship between the composite boldness score of focal fish in inspecting a bass model and their latency to return to feed following an avian attack was different based on the familiarity of nearby conspecifics. This relationship was steeper for focal fish tested with familiar conspecifics than with unfamiliar conspecifics (Figure 9). In other words, the effect of familiarity on the latency to return to feed following an avian attack appears to vary based on the individual's boldness in inspecting a bass model. When comparing the extreme values in personality, the bold and shy individuals in the presence of familiar conspecifics were bolder and shyer than equally bold and shy individuals in the presence of unfamiliar conspecifics. Although significant, the observed interaction between familiarity and the composite boldness score of focal fish may have been driven by the few very bold and very shy individuals (Figure 9) and consequently should be interpreted cautiously.

To conclude, female Eastern mosquitofish did not prefer to associate with familiar individuals in a standardized dichotomous choice experiment. Additionally, the presence of familiar conspecifics did not appear to increase significantly the boldness of the focal fish, although there may be a mild effect. There was, however, a significant interaction between the familiarity of the stimulus shoal and the focal fish's composite boldness score. Additionally, a significant correlation between the predator inspection behaviour of 
focal individuals and their latency to return to feed following an avian attack was detected. Female Eastern mosquitofish have been seldom used in familiarity and shoaling preference studies. Although my results have limitations, this species could prove useful in future studies owing to its widespread abundance and the observed variation in boldness.

\section{Future directions}

Directions for future research could include a repeated study design that would measure the boldness scores for each individual repeatedly to quantify its repeatability (Réale et al., 2007). If boldness is repeatable and if the observed correlation between boldness measures in different contexts are consistent, then a behavioural syndrome may be indicated (Sih et al., 2004). Additionally, the interaction between an individual's boldness and its familiarity with conspecifics on risk-taking behaviour could be further investigated in other species as well as in other personality categories such as exploration and sociability. Although some studies have investigated the effects of familiarity on personality traits, none to my knowledge have investigated potential changes in an individual's personality due to the presence of familiar or unfamiliar conspecifics, as the current study attempted to do.

Another possible direction would be to examine the effect of a familiar freeswimming stimulus fish on the boldness of a focal fish. This would be more representative of natural situations, as the presence of a free-swimming, familiar stimulus fish may entice more predator inspections in focal fish (Chivers et al., 1995). Finally, one could examine the effects of, and interactions between, stimulus shoals consisting of 
familiar or unfamiliar individuals and of bold or shy individuals on the boldness of the focal individual. 


\section{References cited}

Agrillo, C., Dadda, M. and Bisazza, A. 2006. Sexual harassment influences group choice in female mosquitofish. Ethology 112, 592-598.

Alfieri, M.S. and Dugatkin, L.A. 2009. Increased survival as a function of interactions with experienced partners. Ethol. Ecol. Evol.. 21, 101-109.

Barber, I. and Ruxton, G.D. 2000. The importance of stable schooling: do familiar sticklebacks stick together? Proc. R. Soc. Lond. B. 267, 151-155.

Barber, I. and Wright, H.A. 2001. How strong are familiarity preferences in shoaling fish? Anim. Behav. 61, 975-979.

Barber, I., Huntingford, F.A. and Crompton, D.W.T. 1995. The effect of hunger and cestode parasitism on the shoaling decisions of small freshwater fish. J. Fish Biol. $47,524-536$.

Barber, I., Downey, L.C. and Brathwaite, V.A. 1998. Parasitism, oddity and the mechanism of shoal choice. J. Fish Biol. 53, 1365-1368.

Bee, M.A. and Gerhardt, H.C. 2001. Habituation as a mechanism of reduced aggression between neighboring territorial male bullfrogs (Rana catesbeiana). J. Comp. Psychol. 115, 68-82.

Bell, A.M. 2005. Behavioural differences between individuals and two populations of stickleback (Gasterosteus aculeatus). J. Evol. Biol. 18, 464-473.

Bhat, A. and Magurran, A.E. 2006. Benefits of familiarity persist after prolonged isolation in guppies. J. Fish Biol. 68, 759-766.

Biro, P.A. and Post, J.R. 2008. Rapid depletion of genotypes with fast growth and bold personality traits from harvested populations. Proc. Natl. Acad. Sci. USA. 105, 2919-2922.

Biro, P.A. and Stamps, J.A. 2008. Are animal personality traits linked to life-history productivity? Trends Ecol. Evol. 23, 361-368.

Blumstein, D.T. and Daniel, J.C. 2007. Quantifying Behavior the JWatcher Way. Sinauer Associates, Inc. Sunderland, MA.

Both, C., Dingemanse, N.J., Drent, P.J. and Tinbergen, J.M. 2005. Pairs of extreme avian personalities have highest reproductive success. J. Anim. Ecol. 74, 667-674. 
Botham, M.S. and Krause, J. 2005. Shoals receive more attacks from the Wolf-fish (Hoplias malabaricus Bloch, 1794). Ethology 111, 881-890.

Botham, M.S., Kerfoot, C.J., Louca, V. and Krause, J. 2006. The effects of different predator species on antipredator behaviour in the Trinidadian guppy, Poecilia reticulata. Naturwissenschaften. 93, 431-439.

Brown, G.E. and Smith, R.J.F. 1994. Fathead minnows use chemical cues to discriminate shoalmates from unfamiliar conspecifics. J. Chem. Ecol. 20: 3051 -3061

Brown, C., Burgess, F. and Braithwaite, V.A. 2007. Heritable and experiental effects on boldness in a tropical poeciliid. Behav. Ecol. Sociobiol. 62, 237-243.

Chivers, D.P. and Smith, R.J.F. 1994. Fathead minnows, Pimephales promelas, acquire predator recognition when alarm substance is associated with the sight of unfamiliar fish. Anim. Behav. 48, 597-605.

Chivers, D.P., Brown, G.E. and Smith, R.J.F. 1995. Familiarity and shoal cohesion in fathead minnows (Pimephales promelas): implications for antipredator behaviour. Can. J. Zool.73, 955-960.

Chivers, D.P., Mirza, R.S., Bryer, P.J. and Kiesecker, J.M. 2001. Threat-sensitive predator avoidance by slimy sculpins: understanding the importance of visual versus chemical information. Can. J. Zool. 79, 867-873.

Cote, J., Fogarty, S., Weinersmith, K., Brodin, T. and Sih, A. 2010. Personality traits and dispersal tendency in the invasive mosquitofish (Gambusia affinis). Proc. R. Soc. Lond. B. 277, 1571-1579.

Croft, D.P., Arrowsmith, B.J., Webster, M. and Krause, J. 2004. Intra-sexual preferences for familiar fish in male guppies. J. Fish Biol. 64, 279-283.

Dugatkin, L.A. and Godin, J.-G.J. 1992. Prey approaching predators: a cost-benefit perspective. Ann. Zool. Fennici 29, 233-252.

Dugatkin, L.A. and Wilson, D.S. 1992. The prerequisites for strategic behaviour in bluegill sunfish, Lepomis macrochirus. Anim. Behav. 44, 223-230.

Farmer, N.A., Ribble, D.O. and Miller III, D.G. 2004. Influence of familiarity on shoaling behaviour in Texas and blacktail shiners. J. Fish Biol. 64, 776-782.

Ferreira, T. and Rasband, W. 2010. The ImageJ User Guide. Version 1.43, http://rsbweb.nih.gov/ij/docs/user-guide.pdf. 
Fox, S.F. and Baird, T.A. 1992. The dear enemy phenomenon in the collared lizard, Crotaphytus collaris, with a cautionary note on experimental methodology. Anim. Behav. 44, 780-782.

Fraser, D.F., Gilliam, J.F., Daley, M.J., Le, A.N. and Skalski, G.T. 2001. Explaining leptokurtic movement distributions: intrapopulation variation in boldness and exploration. Am. Nat. 158, 124-135.

Frommen, J.G., Luz, C. and Bakker, T.C.M. 2007. Nutritional state influences shoaling preference for familiars. Zoology 110, 369-376.

Frostman, P. and Sherman, P.T. 2004. Behavioral response to familiar and unfamiliar neighbours in a territorial cichlid, Neolamprologus pulcher. Ichthyol. Res. 51, 283-285.

Godard, R. and Wiley, R.H. 1995. Individual recognition of song repertoires in two wood warblers. Behav. Ecol. Sociobiol. 37, 119-123.

Godin, J.-G.J. 1997. Evading predators. In: Behavioural ecology of teleost fishes (edited by J.-G.J. Godin), Oxford: Oxford University Press, pp. 191-236.

Godin, J.-G.J. and Crossman, S.L. 1994. Hunger-dependent predator inspection and foraging behaviours in the threespine stickleback (Gasterosteus aculeatus) under predation risk. Behav. Ecol. Sociobiol. 34, 359-366.

Godin, J.-G. J. and Davis, S.A. 1995. Who dares, benefits: predator approach behaviour in the guppy (Poecilia reticulata) deters predator pursuit. Proc. R. Soc. Lond. B. 259, 193-200.

Godin, J.-G. J. and Dugatkin, L.A. 1996. Female mating preference for bold males in the guppy, Poecilia reticulata. Proc. Natl. Acad. Sci. USA. 93, 10262-10267.

Gómez-Laplaza, L.M. and Fuente, A. 2007. Shoaling decisions in Angelfish: the roles of social status and familiarity. Ethology 113, 847-855.

Griffiths, S.W. 1997. Preferences for familiar fish do not vary with predation risk in the European minnow. J. Fish Biol. 51, 489-495.

Griffiths, S.W. 2003. Learned recognition of conspecifics by fishes. Fish Fish. 4, 256268.

Griffiths, S.W. and Magurran, A.E. 1997a. Familiarity in schooling fish: how long does it take to acquire? Anim. Behav. 53, 945-949 
Griffiths, S.W. and Magurran, A.E. 1997b. Schooling preferences for familiar fish vary with group size in a wild guppy population. Proc. R. Soc. Lond. B. 264, 547-551

Griffiths, S.W. and Magurran, A.E. 1998. Sex and schooling behaviour in the Trinidadian guppy. Anim. Behav. 56, 689-693.

Griffiths, S.W., Brockmark, S., Höjesjö, J. And Johnsson, J.I. 2004. Coping with divided attention: the advantage of familiarity. Proc. R. Soc. Lond. B. 271, 695-699.

Hay, D.E. and McKinnell, S.M. 2002. Tagging along: association among individual Pacific herring (Clupea pallasi) revealed by tagging. Can. J. Fish. Aquat. Sci. 59, 1960-1968.

Helfman, G.S. 1984. School fidelity in fishes: the yellow perch pattern. Anim. Behav. 32, 663-672.

Hensor, E.M.A., Godin, J.-G.J., Hoare, D.J. and Krause, J. 2003. Effects of nutritional state on the shoaling tendency of banded killifish, Fundulus diaphanus, in the field. Anim. Behav. 65, 663-669.

Hoare, D.J., Ruxton, G.D., Godin, J.-G.J. and Krause, J. 2000. The social organization of free-ranging fish shoals. Oikos. 89, 546-554.

Hoare, D.J., Couzin, I.D., Godin, J.-G.J. and Krause, J. 2004. Context-dependent group size choice in fish. Anim. Behav. 67, 155-164.

Höjesjö, J., Johnsson, J.I., Petersson, E., Järvi, T. 1998. The importance of being familiar: individual recognition and social behavior in sea trout (Salmo trutta). Behav. Ecol. 9, 445-451.

Jaeger, R.G. 1981. Dear enemy recognition and the costs of aggression between salamanders. Am. Nat. 117, 962-979.

Jönsson, E., Johnsson, J.I. and Björnsson, B.T. 1996. Growth hormone increases predation exposure of rainbow trout. Proc. R. Soc. Lond. B. 263, 647-651.

Kelley, J.L., Graves, J.A. and Magurran, A.E. 1999. Familiarity breeds contempt in guppies. Nature 401, 661-662.

Krause, J. \& Godin, J.-G.J. 1994. Shoal choice in banded killifish (Fundulus diaphanus, Teleostei, Cyprinodontidae): The effects of predation risk, fish size, species composition and size of shoals. Ethology 98, 128-136.

Krause, J. and Ruxton, G.D. 2002. Living in Groups. Oxford: Oxford University Press 
Krause, J., Godin, J.-G.J. and Brown, D. 1996. Size-assortativeness in multi-species fish shoals. J. Fish Biol. 49, 221-225.

Krause, J., Hatmann, N. And Pritchard, V.L. 1999. The influence of nutritional state on shoal choice in zebrafish, Danio rerio. Anim. Behav. 57, 771-775.

Krause, J., Hoare, D.J., Croft, D., Lawrence, J., Ward, A., Ruxton, G.D., Godin, J.-G.J. and James, R. 2000. Fish shoal composition: mechanisms and constraints. Proc. R. Soc. Lond. B. 267, 2011-2017.

Leblond, C. and Reebs, S.G. 2006. Individual leadership and boldness in shoals of golden shiners (Notemigonus crysoleucas). Behaviour 143, 1263-1280.

Lee-Jenkins, S.S.Y. and Godin, J.-G.J. 2009. Social familiarity and shoal formation in juvenile fishes. J. Fish Biol. 76, 580-590.

Leiser, J.K. and Itzkowitz, M. 1999. The benefits of dear enemy recognition in threecontender convict cichlid (Cichlasoma nigrofasciatum) contests. Behaviour 136, 983-1003.

Magurran, A.E. and Nowak, M.A. 1991. Another battle of the sexes: the consequences of sexual asymmetry in mating costs and predation risk in the guppy. Proc. R. Soc. Lond. B. 246, 31-38.

Magurran, A.E., Seghers, B.H., Shaw, P.W., and Carvalho, G.R. 1994. Schooling preferences for familiar fish in the guppy, Poecilia reticulata. J. Fish Biol. 45, 401-406.

McRobert, S.P. and Bradner, J. 1998. The influence of body coloration on shoaling preferences in fish. Anim. Behav. 56, 611-615.

Metcalfe, N.B. and Thomson, B.C. 1995. Fish recognize and prefer to shoal with poor competitors. Proc. R. Soc. Lond. B. 259, 207-210.

Milinski, M., Luthi, J.H., Eggler, R. \& Parker, G.A. 1997. Cooperation under predation risk: experiments on costs and benefits. Proc. R. Soc. Lond. B. 264, 831-837.

Morrell, L.J., Hunt, K.L., Croft, D. and Krause, J. 2007. Diet, familiarity and shoaling decisions in guppies. Anim. Behav. 74, 311-319.

Murphy, K.E. and Pitcher, T.J. 1997. Predator attack motivation influences the inspection behaviour of European minnows. J. Fish Biol. 50, 407-417. 
Pike, T.W., Samanta, M., Lindström, J. and Royle, N.J. 2008. Behavioural phenotype affects social interactions in an animal network. Proc. R. Soc. Lond. B. 275, 25152520 .

Pitcher, T. 1992. Who dares, wins: the function and evolution of predator inspection behaviour in shoaling fish. Neth. J. Zool. 42, 371-391.

Pitcher, T.J. and Parrish, J.K. 1993. Functions of shoaling behaviour in teleosts. In Behaviour of Teleost Fishes, $2^{\text {nd }}$ edn (edited by T.J. Pitcher), London: Chapman and Hall, pp. 363-439

Porter, R.H., Desire, L., Bon, R. \& Orgeur, P. 2001. The role of familiarity in the development of social recognition by lambs. Behaviour 138, 207-219

Pyke, G.H. 2005. A review of the biology of Gambusia affinis and G. holbrooki. Rev. Fish Biol. Fish. 15, 339-365.

Qualls, C.P. and Jaeger, R.G. 1991. Dear enemy recognition in Anolis carolinensis. J. Herpetol. 25, 363-364.

Réale, D., Reader, S.M., Sol, D., McDougall, P.T. and Dingemans, N.J. 2007. Integrating animal temperament within ecology and evolution. Biol. Rev. 82, 291-318.

Rehage, J.S. and Sih, A. 2004. Dispersal behavior, boldness, and the link to invasiveness: a comparison of four Gambusia species. Biol. Inv. 6, 379-391.

Seppä. T., Laurila, A., Peuhkuri, N., Piironen, J. and Lower, N. 2001. Early familiarity has fitness consequences for Arctic char (Salvelinus alpinus) juveniles. Can. J. Fish. Aquat. Sci. 58, 1380-1385.

Sih, A., Bell, A.M., Johnson, J.C. and Ziemba, R. 2004. Behavioral syndromes: an integrative overview. Q. Rev. Biol. 79, 241-277.

Stamps, J.A. 2007. Growth-mortality tradeoffs and "personality traits" in animals. Ecol. Lett. 10, 355-363.

Swaney, W., Kendal, J., Capon, H., Brown, C. and Laland, K.N. 2001. Familiarity facilitates social learning of foraging behaviour in the guppy. Anim. Behav. 62, 591-598.

Utne-Palm, A.C. and Hart, P.J.B. 2000. The effects of familiarity on competitive interactions between threespined sticklebacks. Oikos 91, 225-232.

Waas, J.R. and Colgan, P.W. 1994. Male sticklebacks can distinguish between familiar rivals on the basis of visual cues alone. Anim. Behav. 47, 7-13. 
Ward, A.J.W. and Hart, P.J.B. 2003. The effects of kin and familiarity on interactions between fish. Fish Fish. 4, 348-358.

Ward, A.J.W. and Hart, P.J.B. 2005. Foraging benefits of shoaling with familiars may be exploited by outsiders. Anim. Behav. 69, 329-335.

Ward, A.J.W., Botham, M.S., Hoare, D.J., James, R., Broom, M., Godin, J.-G.J. and Krause, J. 2002. Association patterns and shoal fidelity in the three-spined stickleback. Proc. R. Soc. Lond. B. 269, 2451-2455.

Ward, A.J.W, Axford, S. and Krause, J. 2003. Cross-species familiarity in shoaling fishes. Proc. R. Soc. Lond. B. 270, 1157-1161.

Ward, A.J.W., Thomas, P., Hart, P.J.B. and Krause, J. 2004. Correlates of boldness in three-spined sticklebacks (Gasterosteus aculeatus). Behav. Ecol. Sociobiol. 55, 561-568.

Ward, A.J.W., Holbrook, R.I., Krause, J. and Hart, P.J.B. 2005. Social recognition in sticklebacks: the role of direct experience and habitat cues. Behav. Ecol. Sociobiol. 57, 575-583.

Webster, M.M., Ward, A.J.W. and Hart, P.J.B. 2007. Boldness is influenced by social context in threespine stickleback (Gasterosteus aculeatus). Behaviour 144, 351 371.

Wiley, R.H., Steadman, L., Chadwick, L. And Wollerman, L. 1999. Social inertia in white-throated sparrows results from recognition of opponents. Anim. Behav. 57, 453-463.

Wilson, D.S., Clark, A.B., Coleman, K. and Dearstyne, T. 1994. Shyness and boldness inhumans and other animals. Trends Ecol. Evol. 9, 442-446.

Wilson, A.D.M., Godin, J.-G.J. and Ward, A.J.W. 2010. Boldness and reproductive fitness correlates in the Eastern mosquitofish, Gambusia holbrooki. Ethology 116, 96-104. 